\title{
Molecular identification of Bulinus spp. intermediate host snails of Schistosoma spp. in crater lakes of western Uganda with implications for the transmission of the Schistosoma haematobium group parasites
}

Immaculate Tumwebaze ${ }^{{ }^{*},}$, Catharina Clewing ${ }^{1}$, Marie Claire Dusabe ${ }^{2}$, Julius Tumusiime ${ }^{3}$, Grace Kagoro-Rugunda ${ }^{3}$, Cyril Hammoud ${ }^{4,5}$ and Christian Albrecht ${ }^{1,3}$

\begin{abstract}
Background: Human schistosomiasis is the second most important tropical disease and occurs in two forms in Africa (intestinal and urogenital) caused by the digenetic trematodes Schistosoma mansoni and Schistosoma haematobium, respectively. A proposed recent shift of schistosomiasis above a previously established altitudinal threshold of $1400 \mathrm{~m}$ above sea level in western Ugandan crater lakes has triggered more research interest there.

Methods: Based on extensive field sampling in western Uganda and beyond and employing an approach using sequences of the mitochondrial barcoding gene cytochrome c oxidase subunit 1 (cox1) this study aims were: (i) identification and establishment of the phylogenetic affinities of Bulinus species as potential hosts for Schistosoma spp.; (ii) determining diversity, frequency and distribution patterns of Bulinus spp.; and (iii) establishing genetic variability and phylogeographical patterns using Bayesian inference and parsimony network analyses.

Results: Out of the 58 crater lakes surveyed, three species of Bulinus snails were found in 34 crater lakes. Bulinus tropicus was dominating, Bulinus forskalii was found in two lakes and Bulinus truncatus in one. The latter two species are unconfirmed potential hosts for S. haematobium in this region. However, Bulinus tropicus is an important species for schistosomiasis transmission in ruminants. Bulinus tropicus comprised 31 haplotypes while both $B$. forskalii and $B$. truncatus exhibited only a single haplotype in the crater lakes. All species clustered with most of the haplotypes from surrounding lake systems forming source regions for the colonization of the crater lakes.

Conclusions: This first detailed malacological study of the crater lakes systems in western Uganda revealed presence of Bulinus species that are either not known or not regionally known to be hosts for S. haematobium, the causing agent of human urogenital schistosomiasis. Though this disease risk is almost negligible, the observed dominance of B. tropicus in the crater lakes shows that there is a likelihood of a high risk of infections with Schistosoma bovis. Thus, extra attention should be accorded to safeguard wild and domestic ruminants in this region as the population benefits from these animals.
\end{abstract}

\footnotetext{
*Correspondence: tumwebazeimmaculate@gmail.com;

immaculate.tumwebaze@allzool.bio.uni-giessen.de

1 Department of Animal Ecology and Systematics, Justus Liebig University

Giessen, Giessen, Germany

Full list of author information is available at the end of the article
} 
Keywords: Bulinus forskalii, Bulinus tropicus, Bulinus truncatus, Schistosoma haematobium, Schistosoma bovis, Neglected tropical disease, Schistosomiasis surveillance

\section{Background}

Schistosomiasis is an important tropical disease especially in sub-Saharan Africa, with more than $90 \%$ of the disease burden [1] and the second most important public health disease after malaria [1,2]. Schistosomiasis is a parasitic disease transmitted by planorbid gastropods. Human schistosomiasis in Africa occurs in two forms (intestinal and urogenital), caused by the digenetic trematodes Schistosoma mansoni and Schistosoma haematobium, respectively. Urogenital schistosomiasis accounts officially for two-thirds of all cases [3], a figure that might be too optimistic as the real prevalence of the disease is potentially underestimated by a factor of three [4]. The already important direct impact of urogenital schistosomiasis is worsened by its established role in cancer epidemics and AIDS epidemics in Africa (reviewed in [5]), besides the long recognized roles in other pathologies and diseases such as haematuria and female genital schistosomiasis (reviewed in [6]). Interestingly, S. haematobium is the least studied of the major human schistosomes $[7,8]$.

Unlike in many other regions of sub-Saharan Africa, in Uganda, intestinal rather than urogenital schistosomiasis is considered a major public health problem [9]. Urogenital schistosomiasis, though present has long been assumed to be restricted to a few areas of eastern and northern Uganda [10]. Schistosomiasis studies in Uganda have so far been focused on regional intestinal schistosomiasis [11-14] around the great lake systems of Lake Victoria and Lake Albert. A negligible amount of studies have been conducted on urogenital schistosomiasis and S. haematobium and their planorbid host snails belonging to the genus Bulinus. Today there is no official declaration about any region of Uganda to be completely free of urogenital schistosomiasis. Thus, the status of urogenital schistosomiasis remains an enigma in Uganda.

A recent study [15] has indicated that intestinal schistosomiasis actually occurs above an earlier designated threshold of $1400 \mathrm{~m}$ above sea level (a.s.l.), specifically in crater lakes in western Uganda. For instance, a high rate of intestinal schistosomiasis in travelers after a brief exposure to the high-altitude crater Lake Nyinambuga was reported in 2012 [16]. The Albertine Rift valley region of western Uganda is dominated by mainly two types of freshwater bodies; the three great lakes Albert, Edward, George and about 90 small crater lakes of

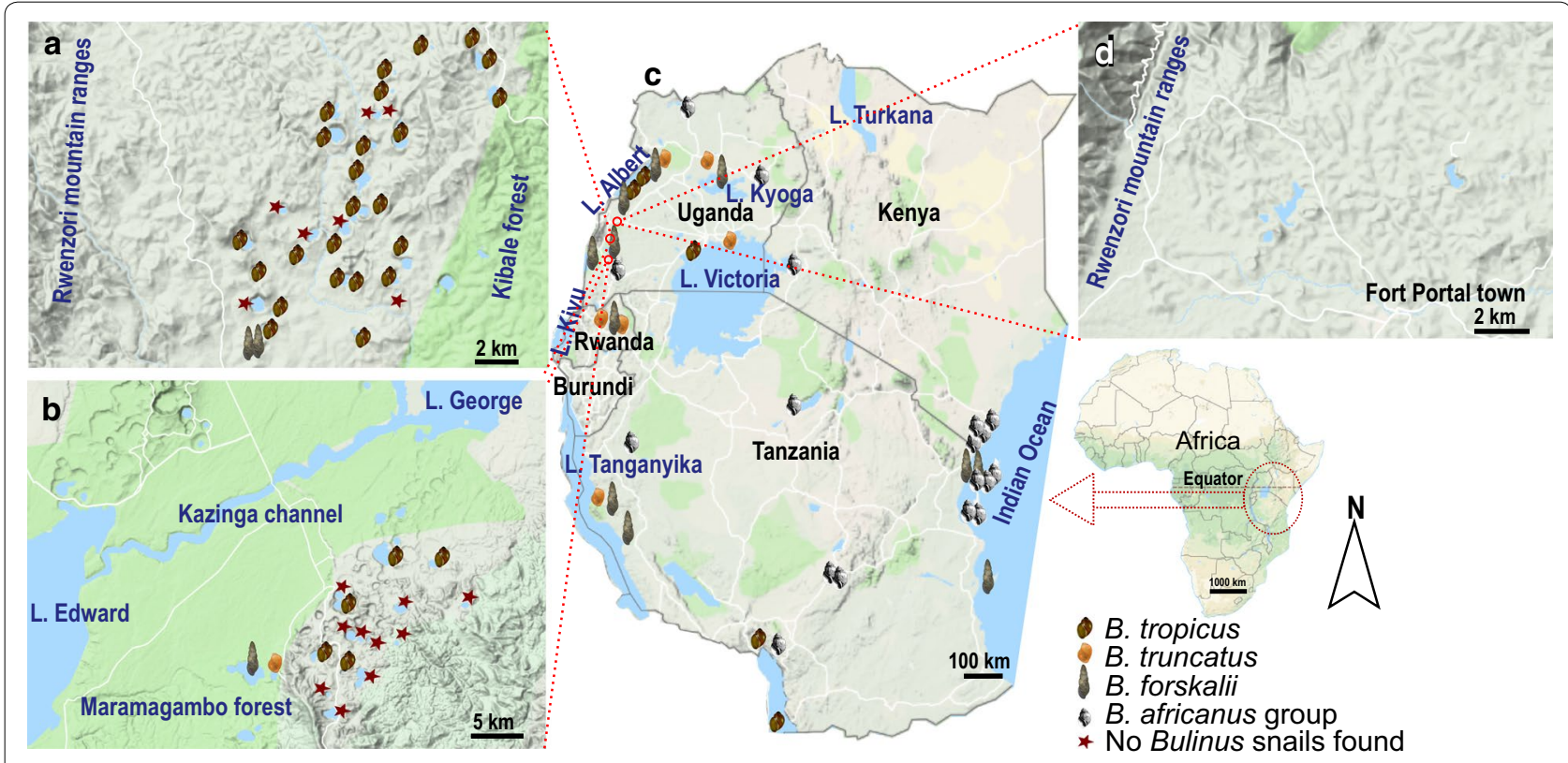

Fig. 1 Sampling sites in the three crater lakes fields in Uganda and at the supra-regional scale. a Ndali-Kasenda crater lakes. b Bunyaruguru crater lakes. c Populations from East Africa. d Fort Portal crater lakes. Snail symbols indicate localities of Bulinus populations studied, whereas a star indicates when sampling did not yield a Bulinus population in the respective crater lake. Note that data for some populations used were retrieved from GenBank (see Table 1) 
varying sizes scattered throughout the region. The crater lakes have originally been divided into four geographical fields of Fort Portal, Ndali-Kasenda, Katwe-Kikorongo and Bunyaruguru [17] (see Fig. 1). They straddle the equator between and are spread along the regional rift valley gradient from $914 \mathrm{~m}$ to $1566 \mathrm{~m}$ elevation [18], with varying limnological characteristics [19] and climatic gradient. The region is one of the most densely populated rural areas in sub-Saharan Africa [20] and is also a tourist destination, attracting local and international travelers.

The potential of urogenital schistosomiasis in Uganda has been neglected, despite the fact that the disease is common in regions nearby such as the Democratic Republic of the Congo (DRC) [21], Tanzania [22] and South Sudan [23]. It has recently been shown that targeting the schistosome intermediate hosts is the most effective of all elimination strategies combating the burden of schistosomiasis [24]. A first step in targeting regional transmission foci is the correct identification of the intermediate hosts [25]. This is particularly true for the Bulinus spp./Schistosoma haematobium system, since Bulinus is a very diverse freshwater gastropod genus of currently recognized 37 species belonging to four species complexes that are morphologically variable [26, 27]. Although there are still some taxonomic issues involved, it has repeatedly been shown that these species complexes can be identified using molecular genetic tools [28-31]. Three of the species complexes are known to occur in regions along the Albertine Rift, namely the $B$. truncatus/B. tropicus complex, the B. forskalii group and the $B$. africanus group [32]. These regions are potentially species source pools for the crater lakes. Given that these groups include potential hosts for S. haematobium, it is important to survey the crater lakes region for snails transmitting human urogenital schistosomiasis. Therefore, enhanced simultaneous mapping and monitoring of strains of urogenital schistosomiasis and their intermediate hosts populations are both necessary to control this disease in areas where it has not been known to occur before. Very little information, however, exists on the mollusc fauna of the crater lakes [33]. This necessitates an assessment of the status of potential host snail species and thus urogenital schistosomiasis in the region.

Based on extensive field sampling in the crater field region and beyond and employing an approach using sequences of the barcoding gene of mitochondrial cytochrome $c$ oxidase subunit 1 ( $\operatorname{cox} 1)$ this study aims are: (i) identification and establishment of the phylogenetic affinities of Bulinus species as potential hosts for Schistosoma spp.; (ii) determining diversity, frequency and distribution patterns of Bulinus spp.; and (iii) establishing genetic variability and phylogeographical patterns.

\section{Methods}

\section{Study area}

This study was conducted in lakes of the three main crater fields in Uganda, between Fort Portal region in the north, Ndali-Kasenda in the middle and Bunyaruguru in the south (Fig. 1). The region is bordered by the vast Rwenzori Mountains in the north-west, the southern shores of Lake Albert in the north and the region of the Queen-Elizabeth National Park (Lake Edward-George) in the south. Most of the crater lakes were formed by faulting and volcanic eruption some 8000 to 10,000 years ago [34]. Bunyaruguru lakes lie on the southern side of the Edward-George system while the rest are located on its northern side. The climate, hydrology, water chemistry and landscape settings are highly heterogeneous between crater fields. Lakes in Fort Portal crater field lie at higher altitude (above $1500 \mathrm{~m}$ a.s.l), than those in the Ndali-Kasenda crater field and Bunyaruguru. Lake Kyaninga (Fig. 2a) is one of the deepest $(220 \mathrm{~m})$ known crater lake in western Uganda [35], although the crater lakes are generally shallow. Some of the lakes are embedded in a still rather natural setting whereas the surroundings of many of the lakes studied are highly disturbed by anthropogenic activities. The lakes are commonly exploited as a water source for humans and livestock consumption (Fig. 2). Furthermore, these lakes are also a main source of food for the local communities using them for fishing. Some of the fish species are introduced. For example, Tilapia zillii, Orechromis leucosticus and Poecilia reticulata were introduced in Lake Nkuruba [36].

\section{Sampling}

Out of 58 crater lakes sampled, 19 were from Bunyaruguru, 33 from Ndali-Kasenda and the 6 remaining from Fort Portal crater field (Table 1). We purposively selected these lakes to cover a range from low altitude (1033 $\mathrm{m}$ a.s.l) to high altitude (1569 $\mathrm{m}$ a.s.l). The selection of a lake and/or sampling site was based on representation of lake field size, lake size class, utilization and lake type as well as accessibility. Lakes of KatweKikorongo field are known to be mainly saline [19] and were therefore not included in this study.

Since the access to the crater lakes is often made difficult by their steep escarpments, we collected snails from one to two localities per crater lake. We used scoop netting and/or dredging sampling techniques to capture snails along the edges of the access point of the lake. A maximum of 40 min sampling time per lake was used. Sampling also involved visual inspection of shoreline vegetation and hand-picking of snails. Samples were derived from depths down to a maximum 


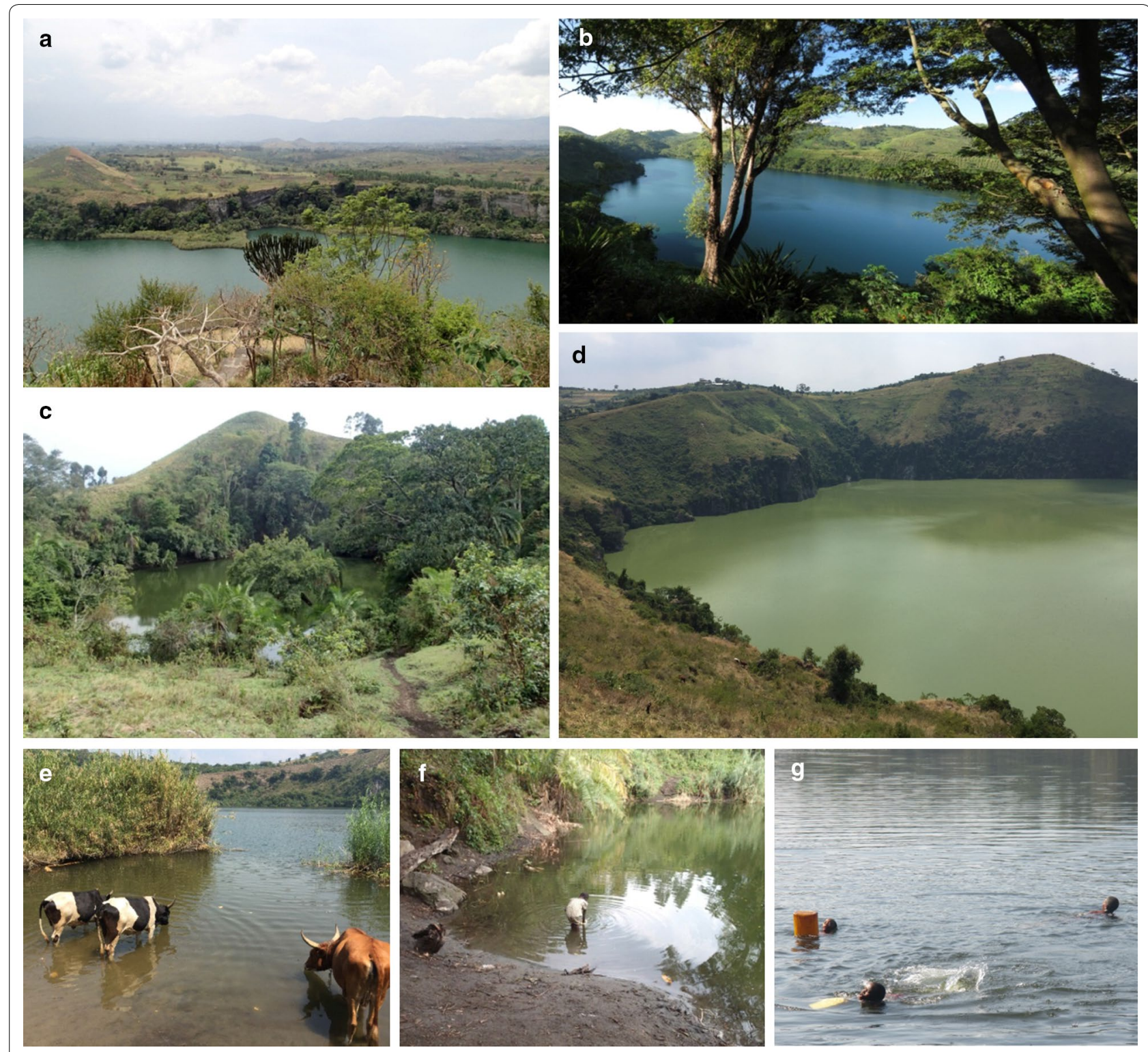

Fig. 2 Impressions from selected crater lakes in western Uganda. a Lake Kyaninga (Fort Portal). b Lake Nyinambuga (Ndali-Kasenda). c Lake Ekikoto (Fort Portal). d Lake Ntambi (Ndali-Kasenda). e Lake Nyamugosani (Ndali-Kasenda). f Lake Kayihara (Fort Portal). g Lake Kako (Bunyaruguru) (Photo credit: C. Albrecht (a, c, f); D. Engelhardt (b); C. Dusabe $(\mathbf{d}, \mathbf{e})$; I. Tumwebaze $(\mathbf{g}))$

of $1.5 \mathrm{~m}$, covering all major habitat types present. The collected snails were fixed in $80 \%$ ethanol and stored at $-20{ }^{\circ} \mathrm{C}$ for subsequent genetic analyses.

\section{DNA isolation, amplification and sequencing}

Prior to DNA isolation, we photographed all specimens with a digital microscope system (KEYENCE VHX-2000; Keyence Deutschland GmbH, Neu-Isenburg, Germany). Genomic DNA was isolated using the CTAB method of DNA extraction [37]. In a few cases, DNA was isolated using DNeasy Blood \& Tissue Kit (Qiagen, Mississauga,
ON, Canada) following the provided instructions. A fragment of the mitochondrial cytochrome $c$ oxidase subunit 1 (cox 1 ) with a target length of $655 \mathrm{bp}$ was amplified using the Folmer region primers LCO1490 [38] and COR722B [39]. PCR reactions were run according to Albrecht et al. [37]. Sanger DNA sequencing was performed on an ABI 3730xl DNA analyzer using the BigDye Terminator Kit (Life Technologies, LGC Genomics GmbH, Berlin, Germany). Vouchers (shells and DNA) are deposited in the University of Giessen Systematics and Biodiversity collection (UGSB, [40]). 


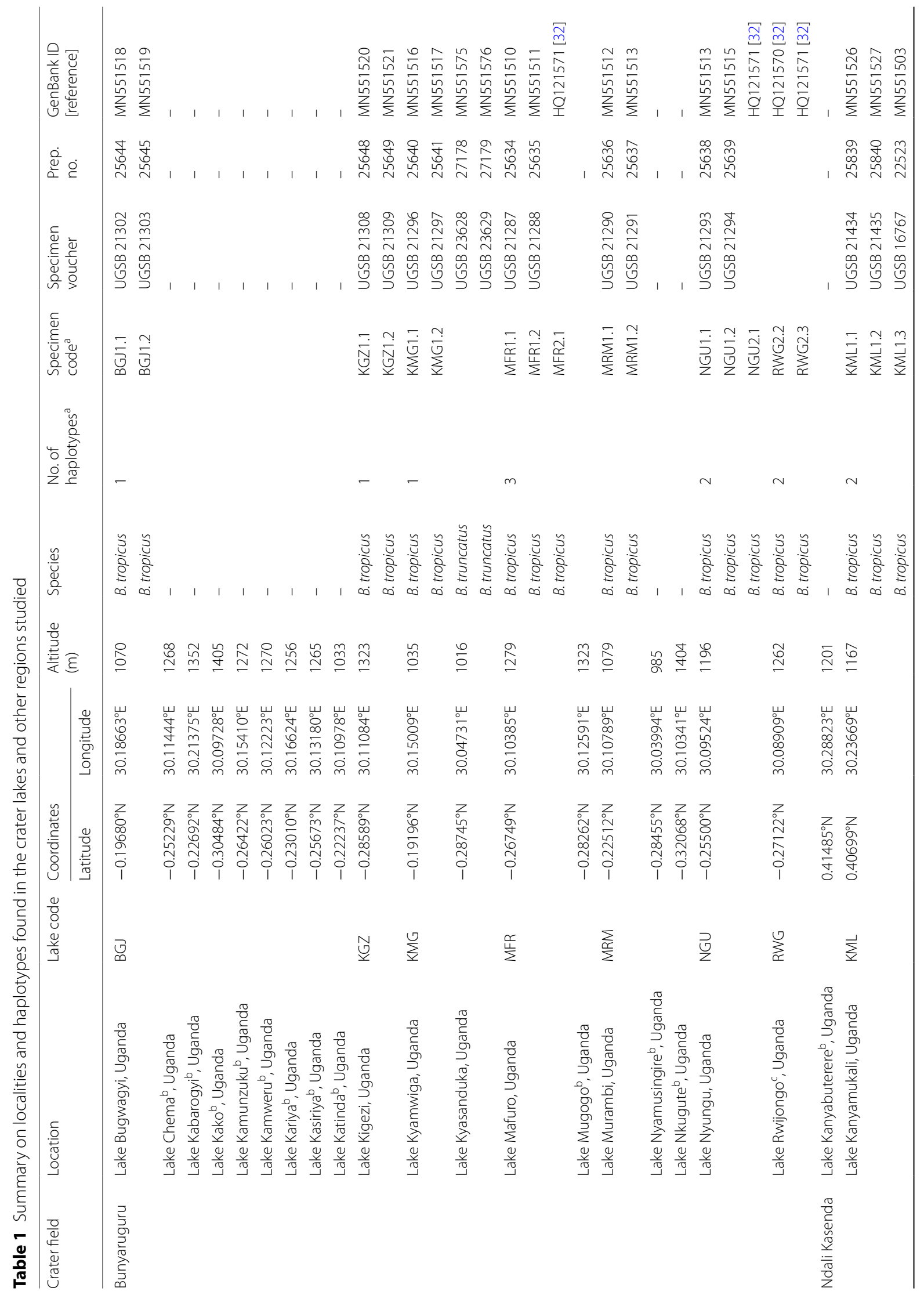




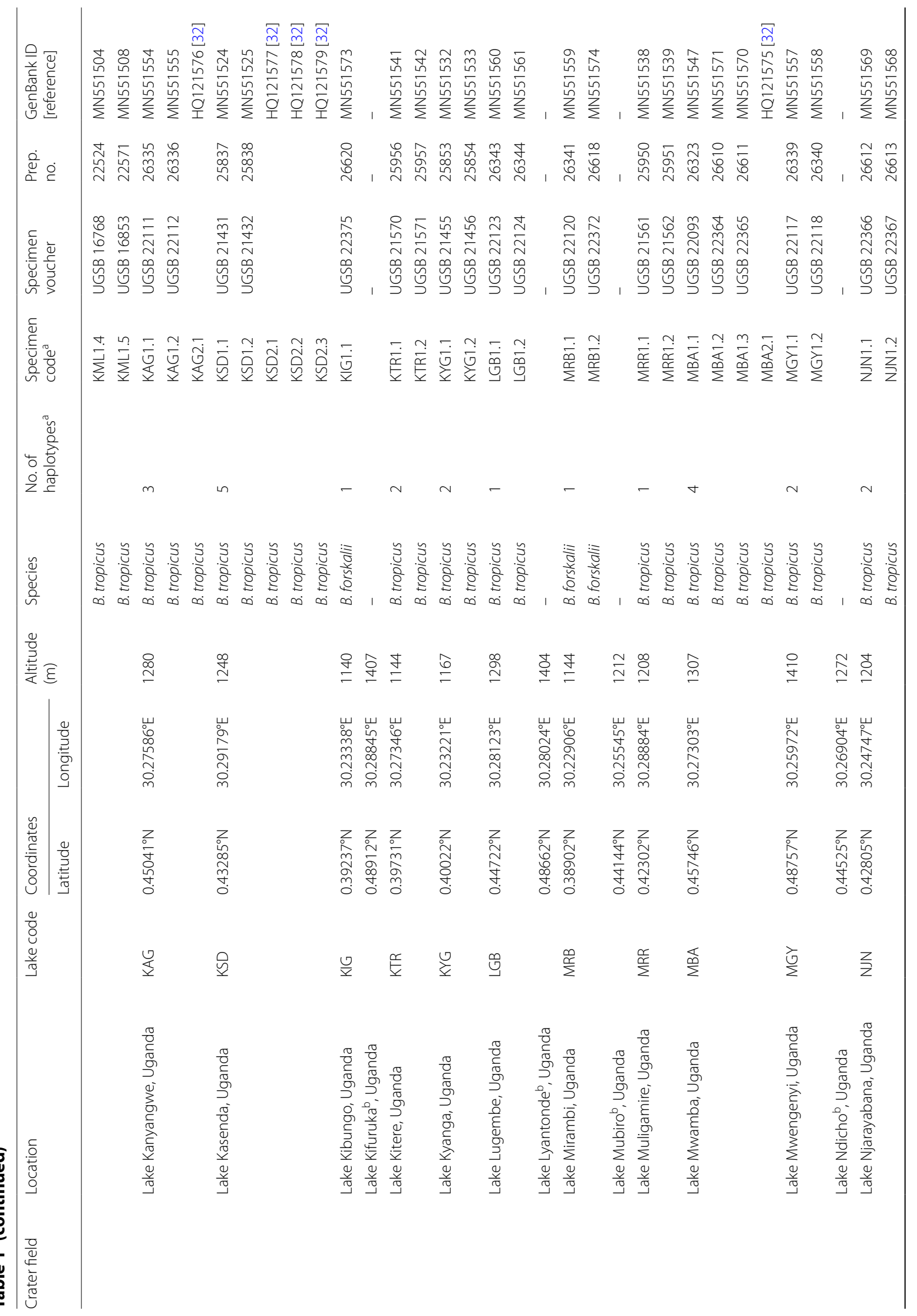




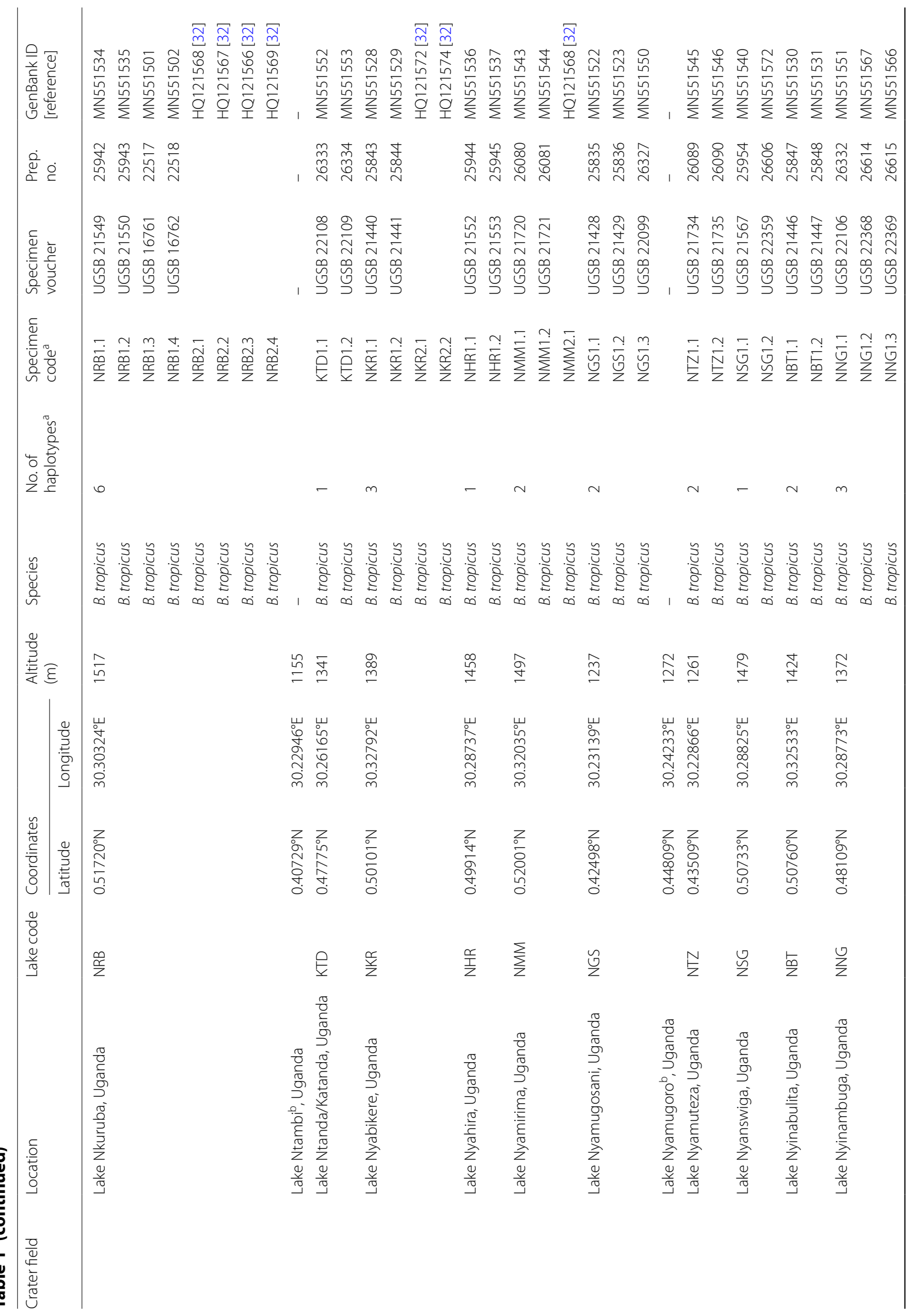




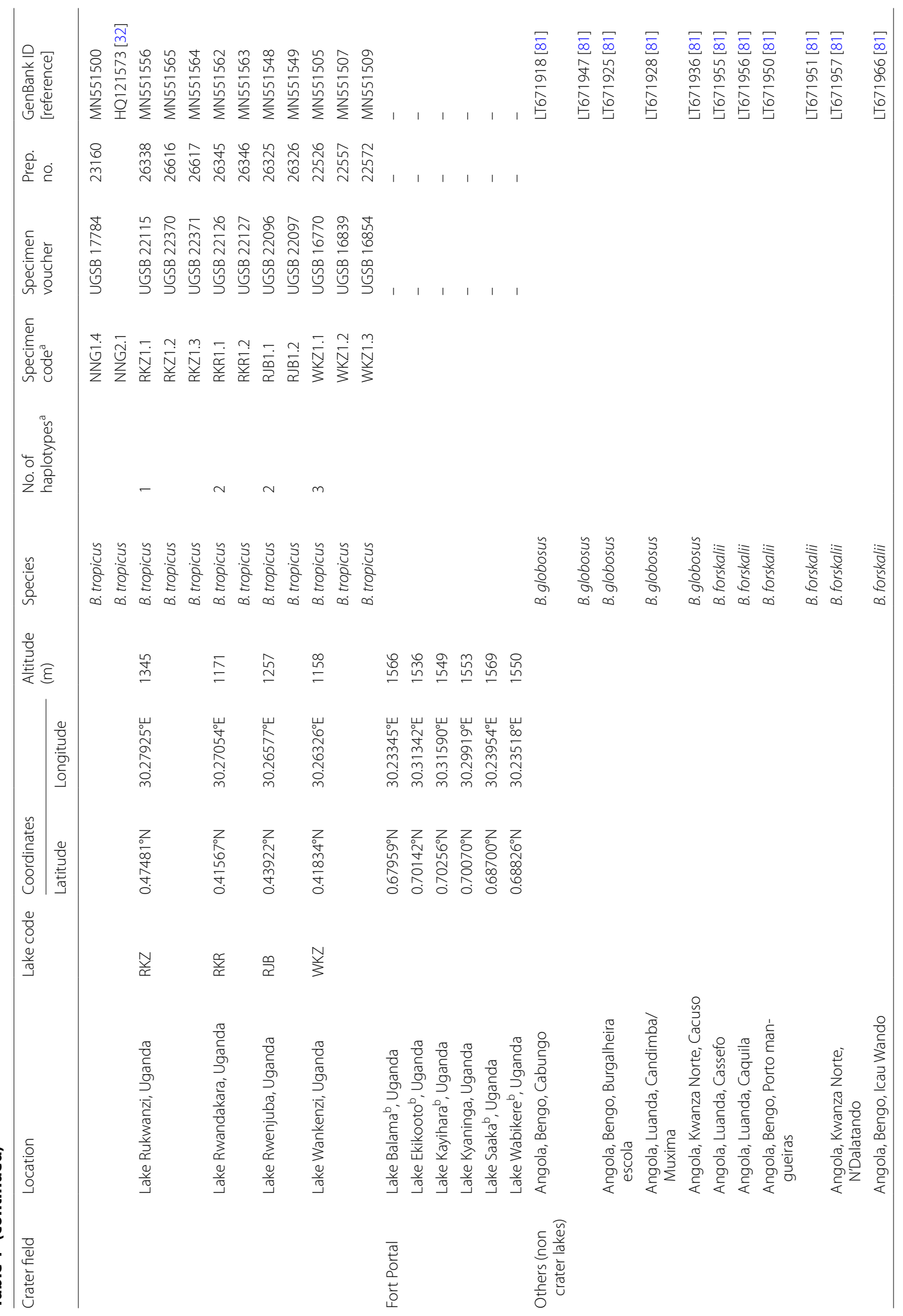




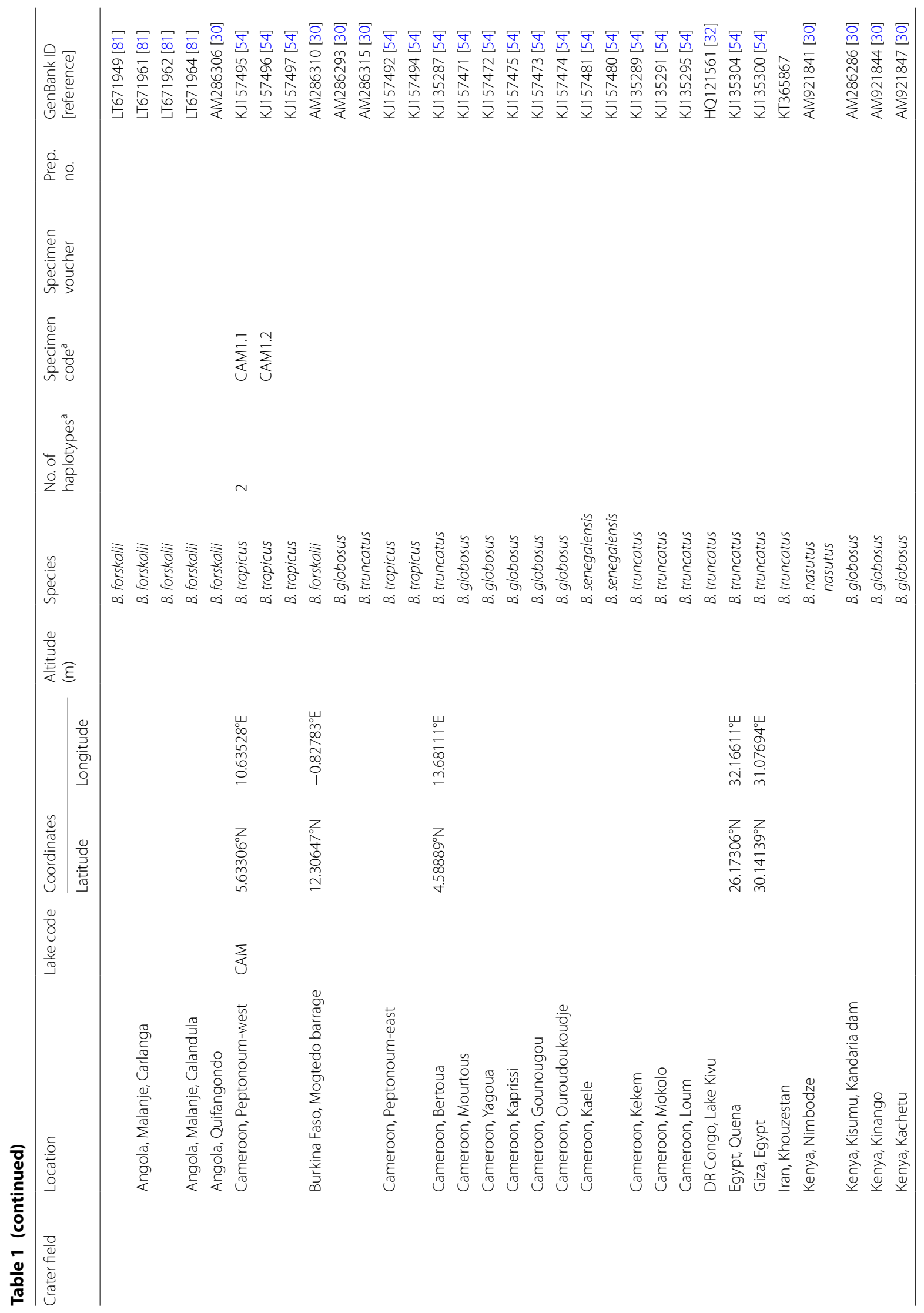




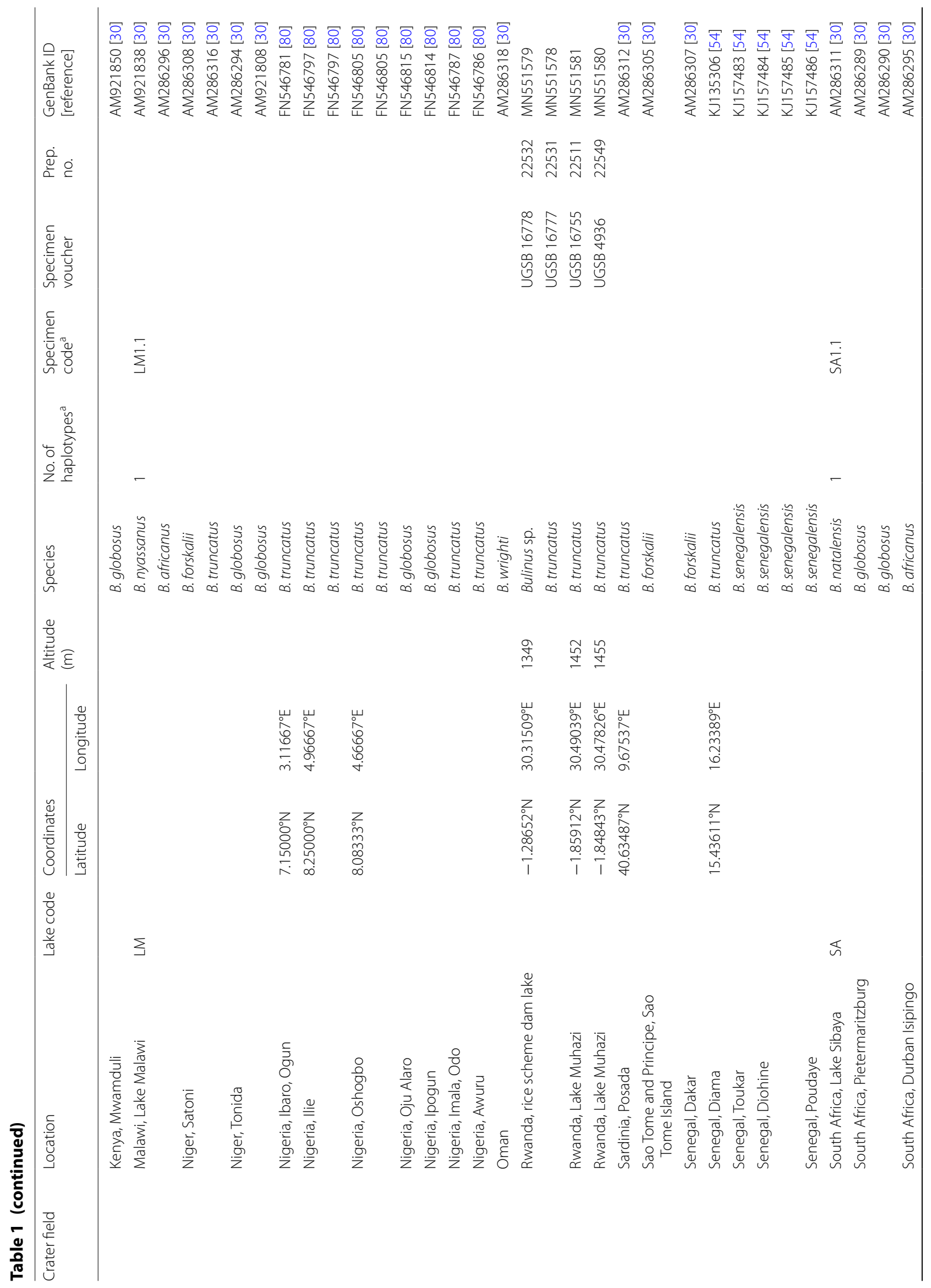




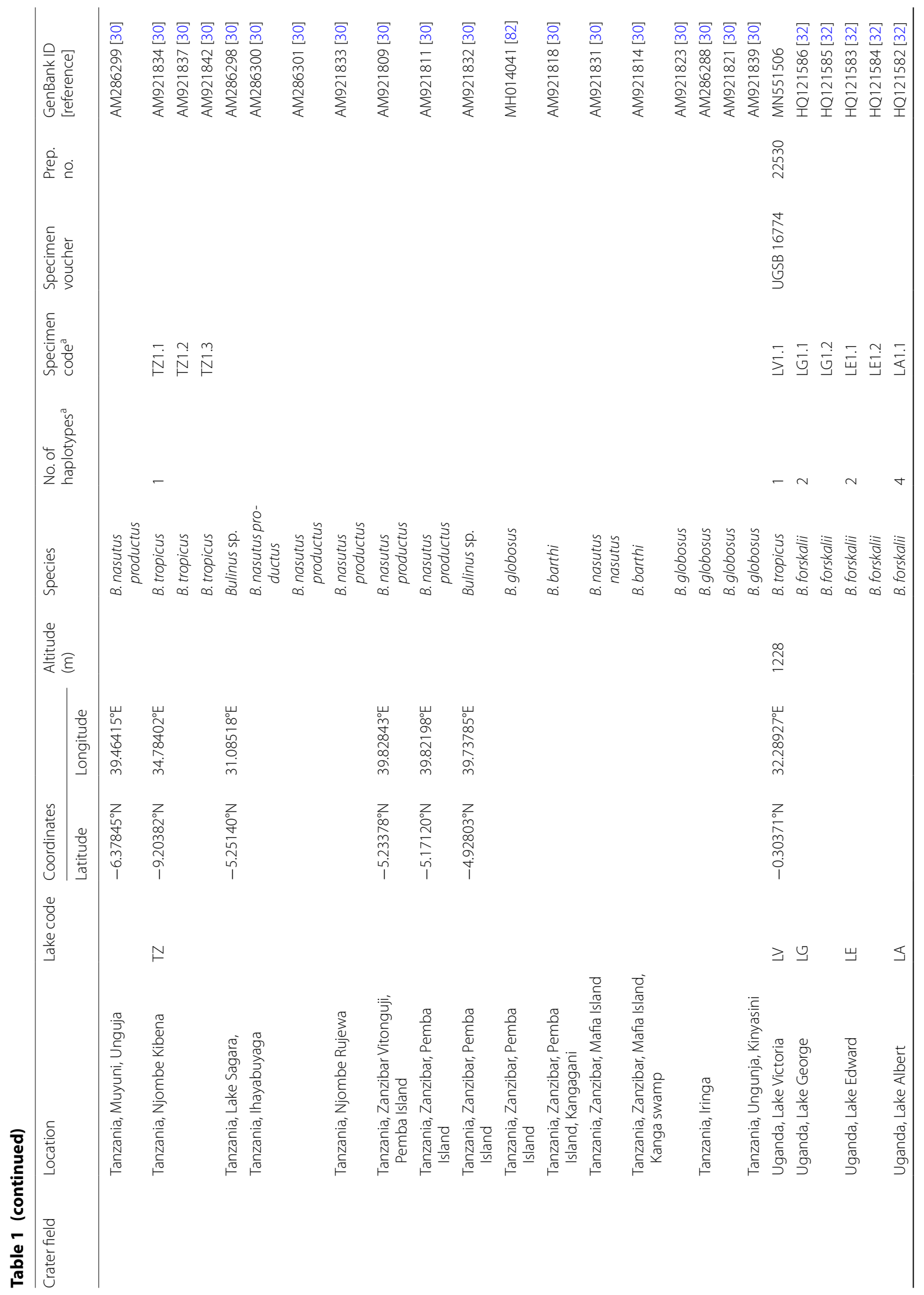




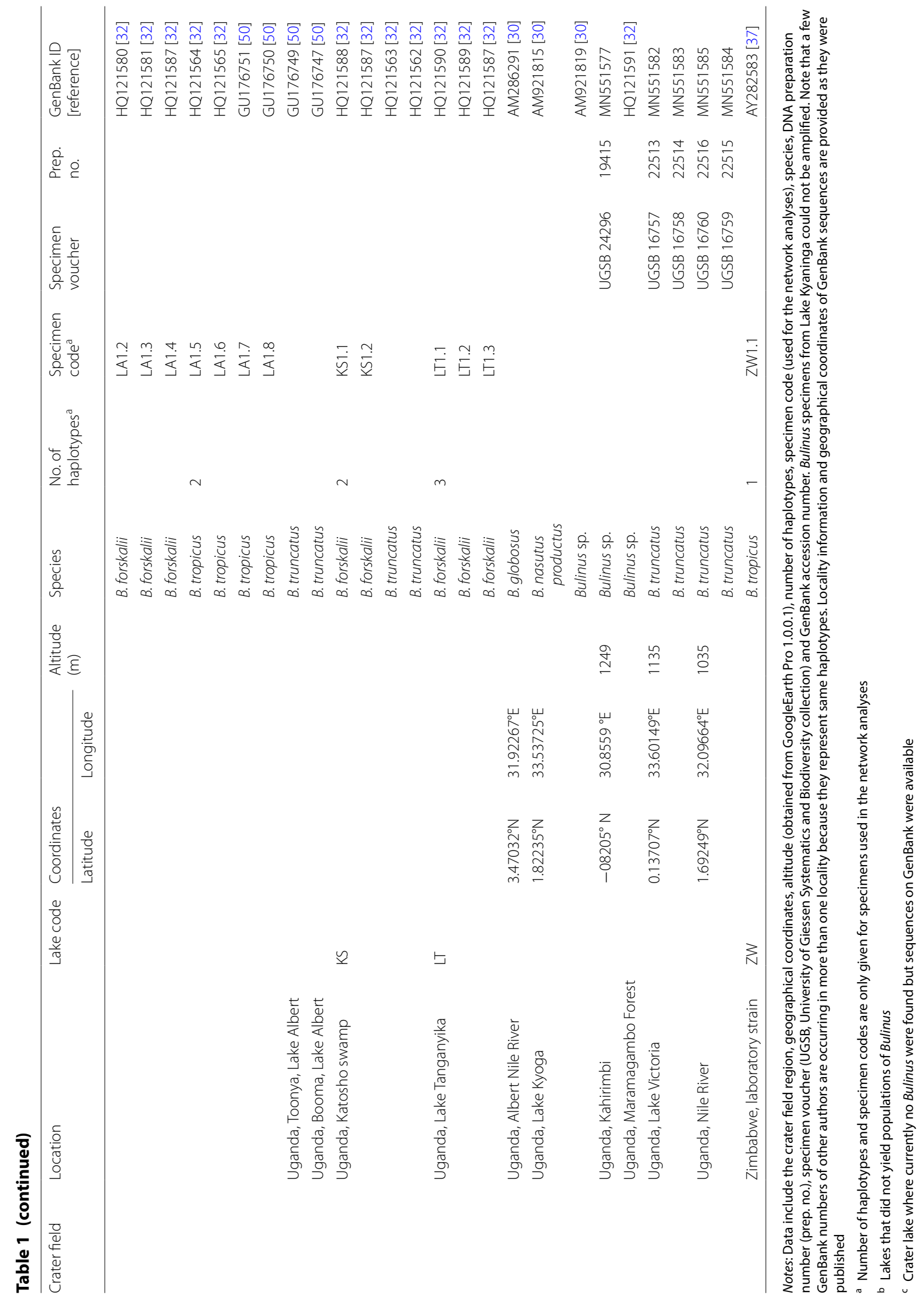




\section{Alignment and dataset composition}

The study comprised specimens from all crater lakes where Bulinus occurred. Furthermore, additional specimens from surrounding watershed and other major aquatic systems were included in order to better trace regional affinities. These are samples from a rice scheme and lakes Muhazi (Rwanda), Mburo, Victoria and the Nile River system in Uganda. In total, material from 43 sampling localities and 85 specimens was used for DNA analyses. Sequences were edited and aligned in BioEdit version 7.0.5 [41]. All 84 newly generated sequences were Blast-searched against the GenBank sequence database. The newly generated sequences were supplemented with all previously published relevant sequences on GenBank. The resulting dataset was aligned using the ClustalW multiple alignment tool in BioEdit after removing redundant haplotypes.

\section{Phylogenetic and phylogeographical analyses}

Bayesian inference analysis was based on a total of 152 sequences (unique haplotypes) originating from our new sampling, as well as from GenBank data. The analysis was performed utilizing MrBayes version 3.2.2 [42] using the following settings: ngen $=4,000,000$, samplefreq $=200$, 'burn-in' $=5000$ (25\%) and HKY $+\mathrm{I}+\Gamma$ as the best-fit substitution model (selected using jModelTest version 2.1.4 [43] under the AIC, AICc and BIC criteria). The effective sample size (ESS) values were examined in Tracer version 1.5.0 [44] indicating for all major parameters values $>800$. Statistical parsimony network analyses for all major clades found to contain crater lake specimens were conducted using TCS version 1.21 [45]. The sub-datasets were selected according to the results of the phylogenetic analysis, two specific clades were selected: Clade 1 and 2). The connection limit was set to either $95 \%$ (Clade 1) or 90\% (Clade 2).

\section{Genetic diversity}

The final cluster analysis of crater lake similarity was based on presence/absence of 31 haplotypes of Bulinus, the Bray-Curtis similarity measure was used (PAST version 3.22) [46].

The relationship of altitude and distribution of haplotype diversity across the crater lake fields was tested using correlation analysis implemented in PAST version $3.22[46]$.

\section{Results \\ Host species identification and diversity}

Out of 58 crater lakes sampled, Bulinus spp. snails were found in 34 belonging to the two crater fields Bunyaruguru and Ndali-Kasenda. Although Bulinus spp. snails were sampled in Lake Kyaninga (Fort Portal), the samples did not yield any DNA for analysis due to technical issues. However, there is a high likelihood that the Bulinus spp. from this lake belong to one of the important S. haematobium hosts, Bulinus globosus, based on the shell shape (Additional file 1: Figure S1c). Lakes Rwijongo (Bunyaruguru), Mubiro and Kanyabutetere (Ndali-Kasenda) yielded Bulinus spp. shells only during the sampling. For Lake Rwijongo, sequences from the GenBank database were available and were included in the analyses. The rest of the crater lakes had either other gastropods or no snails at all. Bulinus spp. co-occurred with Biomphalaria spp. in 28 lakes. Three species of Bulinus were found, i.e. B. forskalii, B. truncatus and B. tropicus. The first was found in only two crater lakes (Mirambi and Kibungo), which are in close proximity located in the Ndali-Kasenda crater field. Bulinus truncatus exclusively occurred in Lake Kyasanduka in the Maramagambo Forest (Bunyaruguru). Bulinus tropicus was dominant, found in the rest of the crater lakes that harbored Bulinus spp. (Table 1 ). In addition, neither $B$. forskalii nor $B$. truncatus occurred sympatrically with $B$. tropicus. All the three $B$. forskalii and the four $B$. truncatus specimens genotyped showed the same haplotypes. Bulinus tropicus portrayed a high variability within and from one lake to another across the crater lakes fields. In total, this study is composed of 33 haplotypes in 34 crater lakes (one haplotype for B. forskalii and B. truncatus and 31 for B. tropicus).

\section{Phylogenetic relationships and biogeographical affinities}

The Bayesian inference analysis showed that Bulinus specimens genotyped for this study are distributed across three of the four Bulinus species groups/complex, specifically the $B$. forskalii and $B$. africanus groups and the B. truncatus/B. tropicus complex (Fig. 3). Bulinus tropicus from the crater lakes clustered exclusively within a

\footnotetext{
(See figure on next page.)

Fig. 3 Bayesian inference phylogenetic tree for Bulinus spp. based on cox 1 gene sequences. Specimens are given with locality information as to country of origin and localities in some cases. The DNA preparation numbers are provided. Crater lake names are provided and the two specific clades of B. forskalii (Clade 1) and B. tropicus (Clade 2) are highlighted with light grey boxes. Crater lake populations are represented at the end of the branch by red boxes, while regional and non-regional (= others) populations are demonstrated by green and grey boxes, respectively. The outgroup Indoplanorbis exustus is not shown. The tree has been partly graphically collapsed (for the full tree see Additional file 2: Figure S2). Bayesian posterior probabilities ( $p p$ ) are given for deeper nodes (when $p p \geq 0.95$ ). The scale-bar represents substitutions per site according to the model of sequence evolution. The number of individuals per haplotype is shown in parentheses for the two specific clades (for details see Figs. 4, 5)
} 


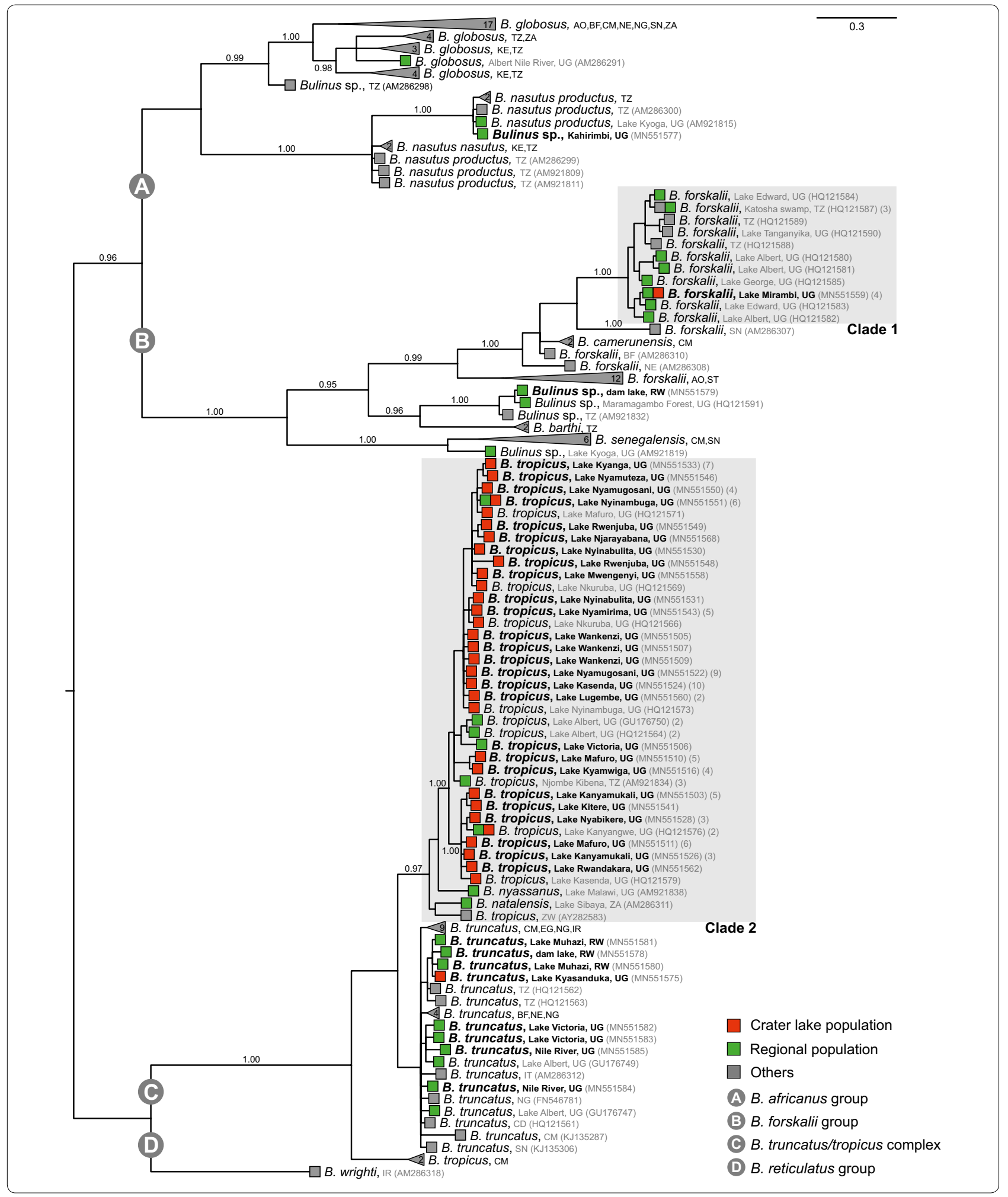

highly supported B. tropicus clade (Clade 2, $\mathrm{pp}=0.97$, see Fig. 3 and Additional file 2: Figure S2) of the $B$. tropicus/B. truncatus complex $(\mathrm{pp}=1.00)$. However, $B$. tropicus specimens from the crater lakes did not form a monophyletic group. Instead, the clade comprising the crater lake samples also included B. tropicus from 
Lake Victoria (MN551506), Lake Albert (GenBank: HQ121564, GU176750) and Njombe Kibena in Tanzania (GenBank: AM921834). Specimens from Lake Malawi (GenBank: AM921838), South Africa (GenBank: AM286311) and a laboratory strain from Zimbabwe (GenBank: AY282583) clustered in a basal position to the $B$. tropicus clade that comprised the crater lake samples. The specimen from Lake Kyasanduka and some specimens of regional populations clustered within the $B$. truncatus assemblage. These populations derived from Lake Victoria, Nile River, Lake Muhazi and other places in Rwanda, which are in close proximity to the crater field systems in western Uganda (Figs. 1, 3). The B. truncatus assemblage also includes populations from locations as far away as Nigeria, Cameroon, or Egypt and Burkina Faso.

The B. forskalii group was genetically very diverse as evidenced by the branch lengths variation with the two crater lake populations clustering with other Ugandan populations from lakes Albert, Edward and George. A distinct and highly supported clade (clade $1, \mathrm{pp}=1.00$, see Fig. 3) also comprised populations from the Katosho swamp (Tanzania) and Lake Tanganyika (Tanzania). A Bulinus sp. from a dam lake connected to a rice field irrigation system in Rwanda (MN551579) belonged to the Bulinus forskalii group but clustered in a different subclade. It also included another Bulinus sp. from Maramagambo Forest, Uganda (GenBank: HQ121591), a place not far from the crater lake fields. Yet another Bulinus sp. from Lake Kyoga clustered with the B. senegalensis subclade of the B. forskalii group.

Another Bulinus sp. (MN551577) from Kahirimbi in Lake Mburo/Nakivale wetland system, about $120 \mathrm{~km}$ south of the crater lakes, belonged the $B$. africanus species group (Fig. 3). It was part of a clade that comprised B. nasutus from Lake Kyoga, Uganda and other regions in Tanzania. Bulinus globosus from Nile River (Moyo, Uganda) was the geographically closest occurrence of this species to the crater lakes in our dataset. Both resolution and support values were low within B. tropicus and B. forskalii clades. The phylogeographical structure for those clades were thus specifically analysed with a parsimony network analysis.

\section{Phylogeographical patterns}

Bulinus forskalii from the crater lakes formed a single network with GenBank haplotypes from the surrounding lakes, i.e. Lake Albert in the north, Lake Edward in the west and Lake George in the east. A few haplotypes from regions outside Uganda, such as Lake Tanganyika and nearby Katosho swamp also appeared in the network, whereas others from Rwanda or the Maramagambo Forest east of Lake Edward did not (Fig. 4). All the three

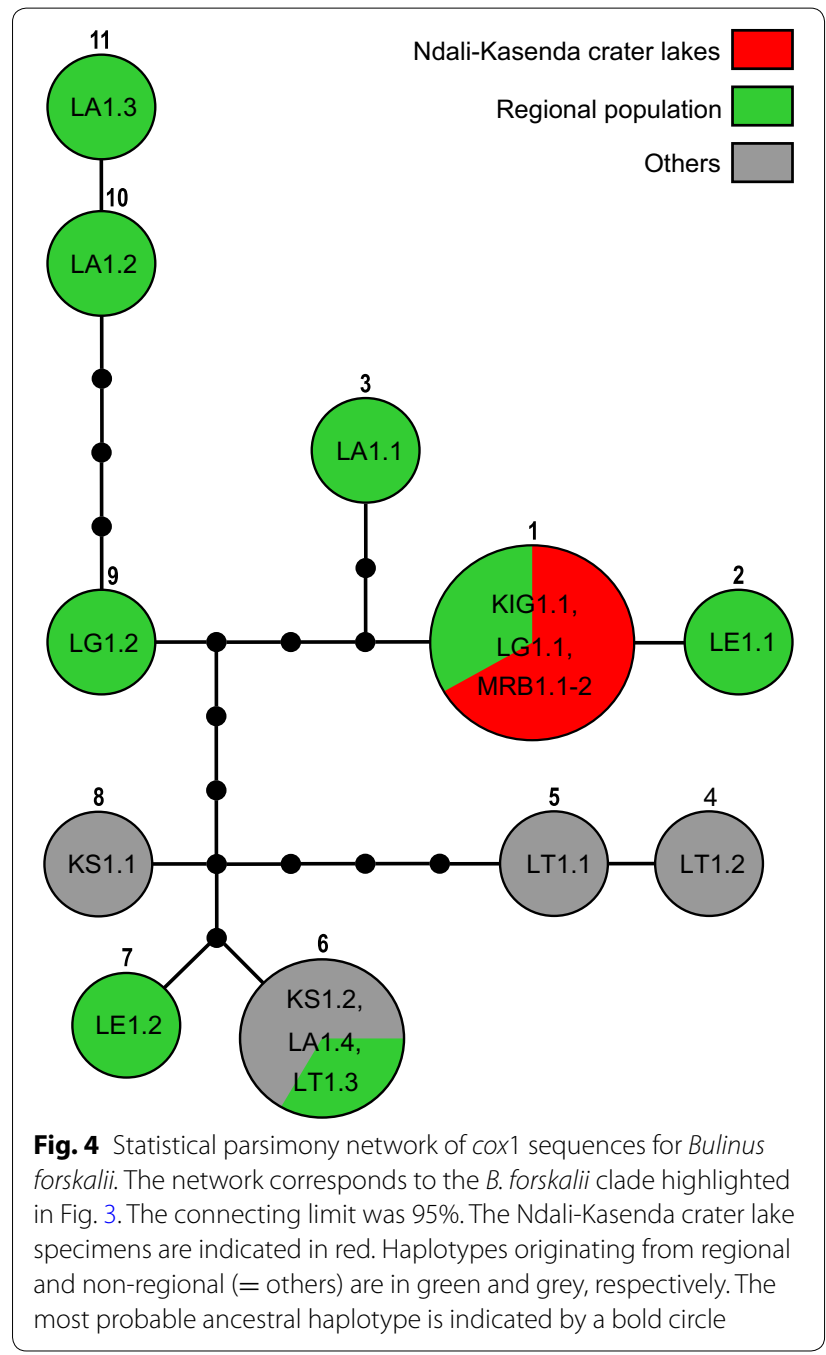

crater lake specimens represented one haplotype and together with a haplotype (GenBank: HQ121586) from Lake George formed the most probable ancestral haplotype for the network. Haplotypes from far away regions were also reconstructed as distantly related. For example, there were 11 and 10 mutational steps between haplotypes from Lake Tanganyika (GenBank: HQ121590, HQ121589). On the other hand, haplotypes from nearby regions such as Lake Edward and Lake George were reconstructed either as relatively similar (e.g. GenBank: HQ21582, HQ21583, HQ121586) or as relatively far distant in terms of mutational steps (e.g. GenBank: HQ121580).

The single haplotype network of $B$. tropicus based on a $90 \%$ connection limit contained 38 haplotypes (Fig. 5). Haplotype 11 (Fig. 5) was present in six lakes in NdaliKasenda was reconstructed as the most probable ancestral haplotype. The haplotypes of both the Ndali-Kasenda and the Bunyaruguru crater fields were very diverse 


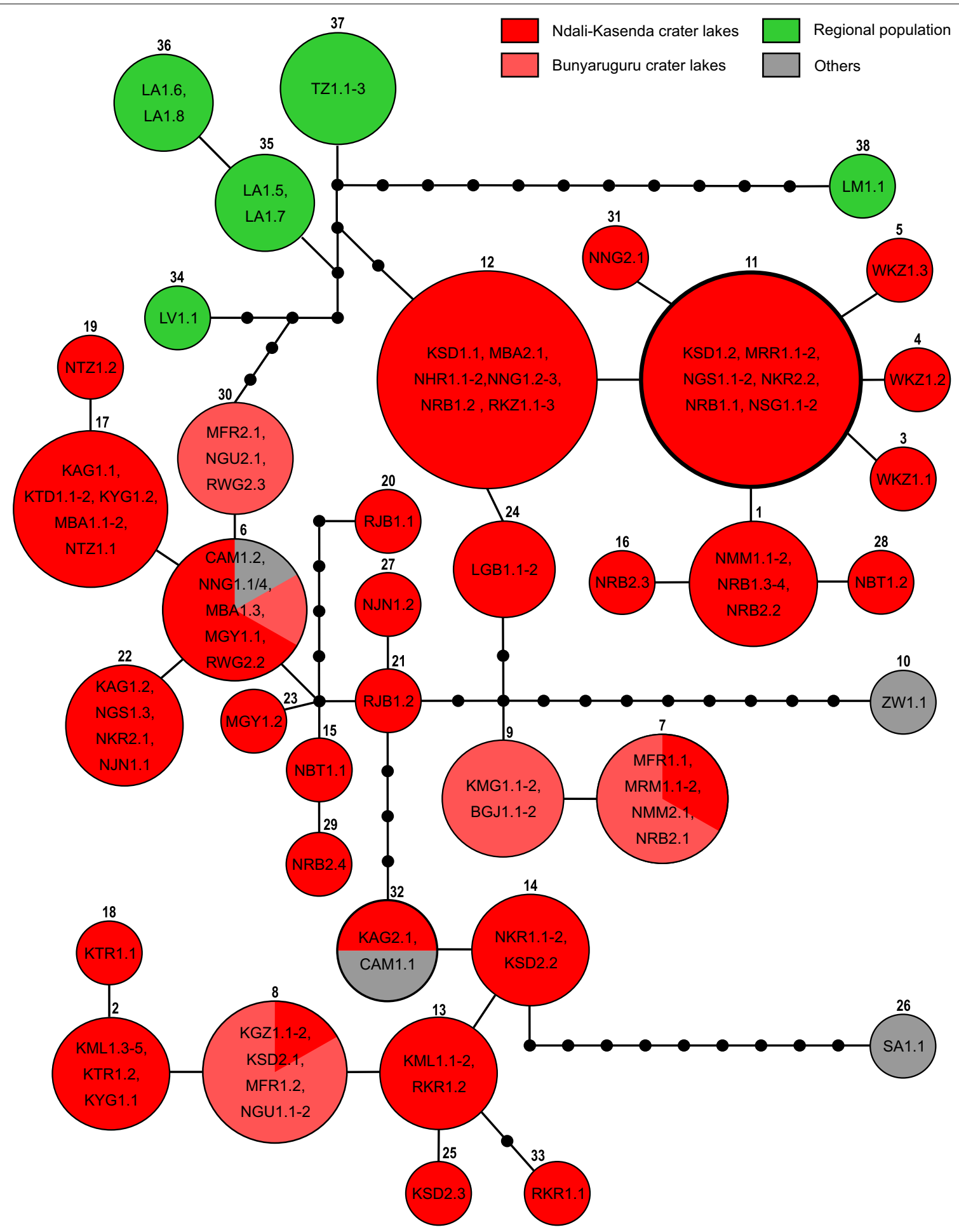

Fig. 5 Statistical parsimony network of cox 1 sequences for Bulinus tropicus. The network corresponds to the B. tropicus clade highlighted in Fig. 3. The connecting limit was $90 \%$. The two crater lakes fields of Ndali-Kasenda and Bunyaruguru are coloured red and light red, respectively. Haplotypes connected but occurring in other systems are represented in green and grey for regional and non-regional (= others) populations respectively. The most probable ancestral haplotype is indicated by a bold circle 
ranging from a few or no mutational steps, to as many as 17.

In most cases, haplotypes of the Ndali-Kasenda crater field were unique with a few exceptions where a haplotype was shared with either samples from the Bunyaruguru crater field (haplotypes 7 and 8 in Fig. 5), outside the region (haplotype 32 in Fig. 5) or both (haplotype 6 in Fig. 5). Lakes Kyamwiga and Bugwagyi of the Bunyaruguru crater field had exclusive haplotypes. Some lakes had quite distantly genetically related haplotypes such as MN551511, MN551510 and HQ121571, all of which are from Lake Mafuro located in the Bunyaruguru crater field. A haplotype from as far as Cameroon was identical to three crater lake samples of the Ndali-Kasenda crater field that are in close proximity to one another and Lake Rwijongo of the Bunyaruguru crater field (haplotype 6 in Fig. 5). Except for the Cameroonian, all haplotypes from outside crater lake systems are unique. These are haplotypes from Lake Victoria, Lake Albert and Tanzania. They belonged to a single group connected to crater lake haplotypes by a minimum of four mutation steps to the Ndali-Kasenda haplotypes via a Tanzanian haplotype (haplotype 37 in Fig. 5), Lake Albert (haplotype 35 in Fig. 5) and five mutation steps to a Bunyaruguru haplotype via a Lake Victoria haplotype (haplotype 34 in Fig. 5). Three haplotypes were extremely distant from the core network, i.e. samples from South Africa (haplotype 26 in Fig. 5), B. nyassanus from Lake Malawi (haplotype 38 in Fig. 5) and the laboratory strain from Zimbabwe (haplotype 10 in Fig. 5).

\section{Genetic diversity}

The cluster analysis based on the presence/absence of haplotypes did not result in a clear pattern (Fig. 6). Whereas some lakes clustered together, others remained unclustered. Lakes Nyungu (NGU), Kigezi (KGZ) and Mafuro (MFR) all belong to the Bunyaruguru crater field cluster together. Other lakes belonging to that crater field such as lakes Bugwagyi (BGJ) Kyamwiga (KMG) were clustered too, whereas Rwijongo (RWG) did not cluster together with any of the two groups in the same crater field. The numerous lakes of the Ndali-Kasenda field formed three main clusters. Lakes Wankenzi (WKZ), Lugembe (LGB), Rwenjuba (RJB) and Nyinabulitwa (NBT) did not cluster to any of the other groups. Some lakes in the two crater fields tended to cluster

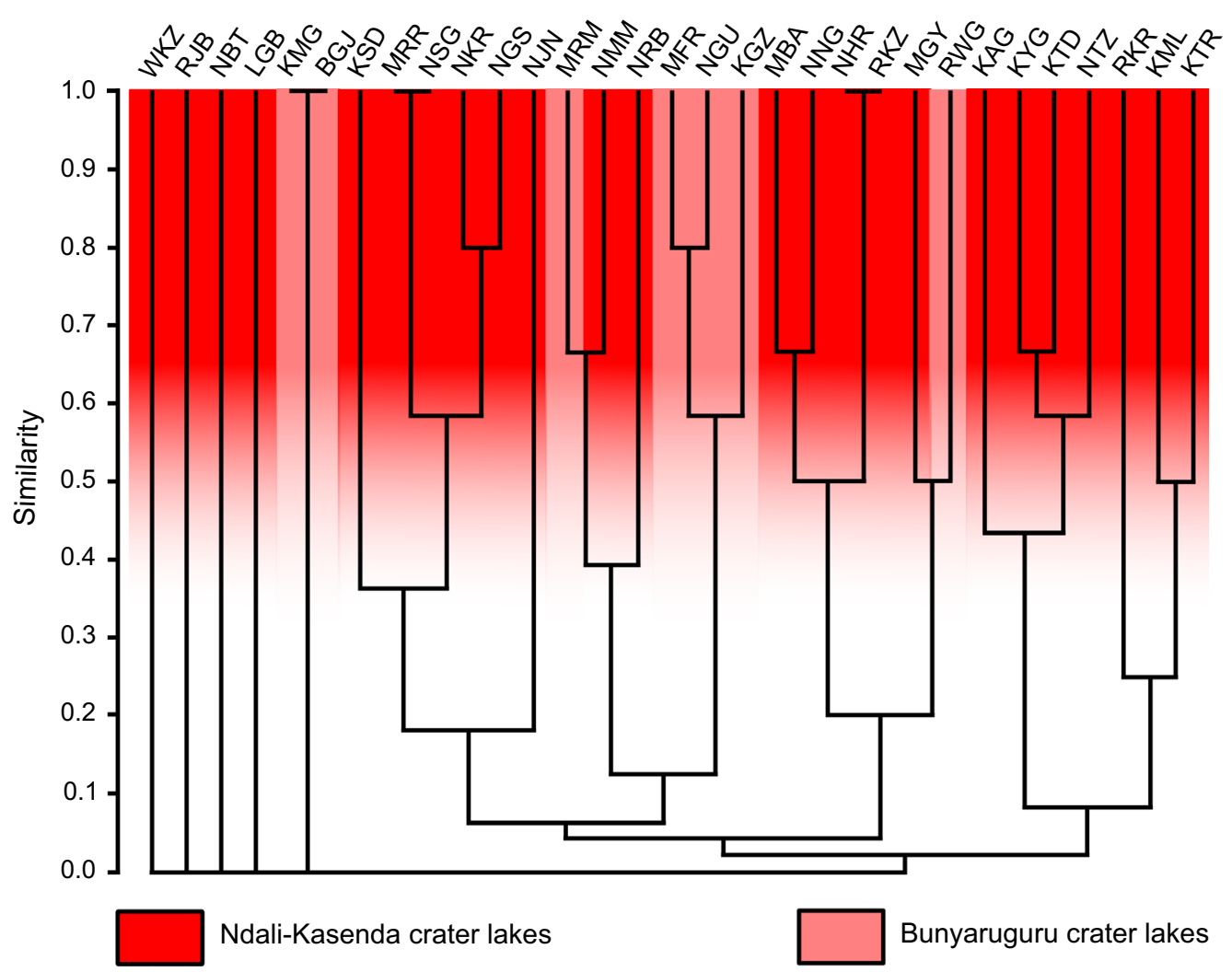

Fig. 6 Cluster analysis of crater lake similarity based on presence/absence of 31 haplotypes of Bulinus tropicus. The Bray-Curtis similarity measure was used. Three letter codes refer to the respective lakes in Table 1. The haplotype matrix is given in Additional file 3: Table S1 


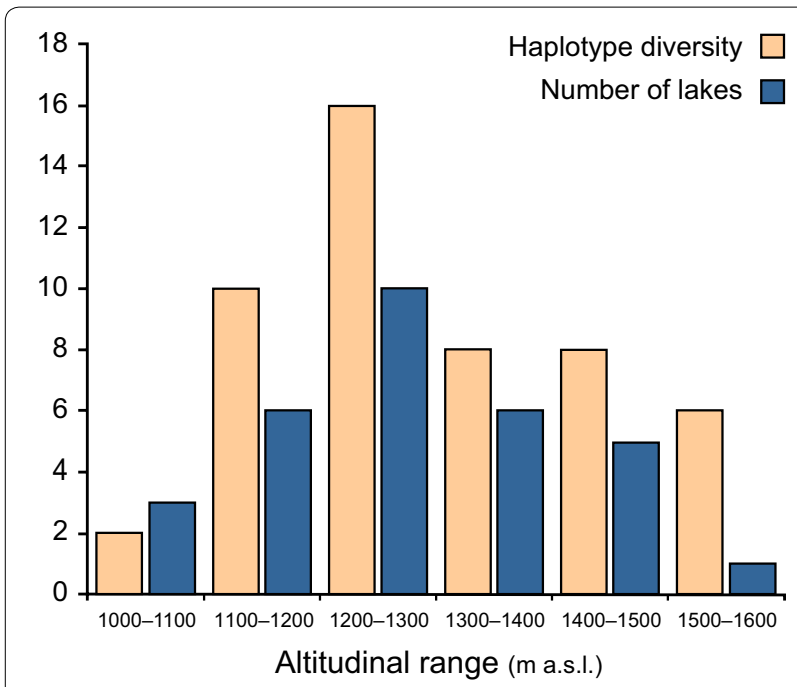

Fig. 7 Haplotype diversity versus increase in altitude according to $100 \mathrm{~m}$ altitudinal bands for 31 unique haplotypes in 31 crater lakes

together, for example Lake Nyamirima (NMM) with Lake Murambi (MRM) and Lake Rwijongo (RWG) with Lake Mwengenyi (MGY). Lakes that came out to be more similar according to this analysis, for example lakes Nyahira (NHR) and Rukwanzi (RKZ), or lakes Nyanswiga (NSG) and Muligamire (MRR) are not geographically related.

\section{Haplotype diversity across the crater lakes' altitudinal gradient}

The distribution of haplotype diversity along the altitude gradient was unimodal (Fig. 7). A high haplotype diversity was realized in an altitude range between 1200 to 1300 m a.s.l., with 16 different haplotypes. Lake Nkuruba with the most haplotype diversity and situated at an altitude of $1517 \mathrm{~m}$ a.s.l) was represented by eight specimens and six unique haplotypes. The lakes in the Bunyaruguru crater field, which are at the lowest altitudes exhibited limited haplotype diversity $(n=6)$. Based on the present dataset, the haplotype diversity was not correlated with altitude $(r=0.26813, P=0.12787)$.

\section{Discussion}

\section{Bulinus species in the crater lakes}

To date, historical records provide very restricted information on molluscs in crater lakes in Uganda [33]. Although Bulinus tropicus has been present there for quite a while already, not much more was known hitherto, except for the study by Nalugwa et al. [32] on Bulinus species complexes in the Albertine Rift, which included a few crater lakes of western Uganda. In this study, Bulinus tropicus by far dominates in the crater lakes, whereas B. forskalii was exclusively found in lakes of Mirambi and Kibungo that are in close proximity. Bulinus forskalii is essentially an Afrotropical species that often occurs in small and even temporary water bodies [26]. It seems less common in colder climates of highlands in eastern Africa and has been found up to $1800 \mathrm{~m}$ a.s.l. in Ethiopia [47]. Bulinus forskalii is not known to be naturally infected with $S$. haematobium (see [48]). Bulinus tropicus is a widespread species in eastern and southern Africa, but unlike its sibling species $B$. truncatus, is apparently not acting as intermediate host for $S$. haematobium, the parasite causing urogenital schistosomiasis [26, 27]. Bulinus tropicus is known to occur up to $2700 \mathrm{~m}$ a.s.l. in Kenya [26]. This species is extremely flexible ecologically, i.e. it exhibits a high tolerance towards cooling and drought conditions and even to only temporary availability of habitat. Such conditions might exist in the crater lakes of western Uganda, where extensive lake level fluctuations over seasonal periods have been documented ([49]; Tumwebaze, own observations from historical satellite images).

This ecological flexibility might be linked to another very interesting finding of the present study, which is the extremely high diversity of haplotypes of B. tropicus in the crater lakes. It almost matches the total range of genetic diversity hitherto known for this species [30]. Given the fact that the present study was not designed as a population study, the real variability might be even higher.

The fact that so far, the majority of the studied Bulinus spp. populations belonged to B. tropicus, does not mean $S$. haematobium strains would not occur in the entire crater lakes region. The sibling tetraploid species $B$. truncatus, a major intermediate host for $S$. haematobium in many regions of Africa, has been found in various places along the Albertine Rift $[32,50]$ and our dataset included populations from nearby areas in Uganda and Rwanda (Fig. 3). Although we found it exclusively in one crater lake, sympatric occurrences of the two species are possible [32]. A presence of tetraploid B. truncatus can therefore not be ruled out without such detailed molecular surveys such as the ones conducted in the present study. The recurrent almost complete absence from the crater lakes of B. truncatus, an ecologically largely flexible species with high colonizing capacity [26], remains somewhat enigmatic. This species has been found confined to altitudes of $2100 \mathrm{~m}$ a.s.l., rarely up to $2400 \mathrm{~m}$ a.s.l. in Ethiopia [26]. It was present in our study in Lake Victoria, the Nile River and Lake Muhazi, Rwanda, all locations in a radius of just c. $250 \mathrm{~km}$. Bulinus globosus, another potential host species, is known from the Nile River, Moyo Province, Uganda [30]. We found another B. nasutus-like species at the Lake Mburo-Nakivale system in southwestern Uganda. B. nasustus has also been found in 
previous work in Lake Kyoga [30] (Fig. 3). It is therefore perhaps just a matter of time and or chance until other species of Bulinus acting as intermediate hosts for human schistosomiasis are to be found in the crater lakes. The absence of members of the $B$. africanus group from the crater lakes is noteworthy though. Prediction as to occurrences of specific snail lineages is difficult since not only time and isolation matter, but also ecology of the small lakes. They are very different from littoral conditions in better studied large lakes such as Albert, Edward and Victoria, for which factors favoring a mitigation of the proliferation of snail populations have been determined to a much greater extent than in other lotic or lentic natural aquatic systems in East Africa [14, 51-53]. The absence of Bulinus in some of the studied crater lakes might be attributed to limnological conditions $[18,19]$. However, 19 lakes where Bulinus was not collected contained other molluscs (Tumwebaze \& Albrecht, unpublished data). Repeated sampling during different seasons might help constructing a more complete picture of Bulinus spp. communities in these lakes.

\section{Phylogenetic relationships and biogeographical affinities}

The phylogenetic study of Bulinus spp. corroborated earlier findings that three major species complexes exist in the Albertine Rift region [32], although only B. tropicus was found to be present then in the crater lakes. Our field sampling complements the previously limited knowledge of the Bulinus spp. communities of the crater lakes based on the previous effort of Nalugwa et al. [32] on a smaller subset of lakes. The phylogenetic affinities of specimens genotyped from potential source populations, i.e. close geographical proximity, revealed a wide range of genetic variability which is interpreted as reflecting the high morphological and ecological flexibility of the species, as well as its extraordinary dispersal capacities. The analyses of the $B$. tropicus subclade (Fig. 3) resulted in few well-supported branches which made tracing a single origin of the crater lakes populations difficult from a phylogenetic analysis. However, the findings support the hypothesis of highly dynamic fluctuations of populations coming into the crater lakes on a potentially frequent basis. It was unexpected to find haplotypes that are known from other places far away in East Africa or even western Africa (Cameroon) in the crater lakes studied here. For the present dataset, the origin of the haplotype network was reconstructed for a haplotype occurring in six lakes of the Ndali-Kasenda lake region, likely reflecting the extraordinary diversity in the DNA data. Whereas environmental parameters might account for phenotypic plasticity observed in the B. truncatus/B. tropicus complex, no such direct relationships have been shown for the degree of genetic variation. It might be in fact one of the reasons why $B$. tropicus is refractory to human-infecting schistosomes [26]. Both B. forskalii and B. truncatus exhibit less genetic variation on similar geographical scales $[25,54,55]$. Bulinus forskalii from the crater lakes clearly belongs to a very distinct clade of Albertine Rift valley populations and colonization likely happened from nearby sources such as Lakes George, Albert and Edward. Interestingly, this clade also comprises haplotypes from further south, namely Lake Tanganyika. Other species of the $B$. forskalii group that are geographically closer, such as Lake Kyoga or Rwanda or even the Maramagambo Forest in Queen Elizabeth National Park, Uganda, do represent quite distinct lineages.

\section{Phylogeography and lake patterns}

Since the crater lakes in western Uganda are roughly 8000 to 10,000 years-old [34], the variation observed is not likely to have developed in that setting given the general mutation rate of the molecular marker cox 1 , even if we consider potentially higher rates under tropical conditions [56]. It is worth noting that the unique haplotypes often differed by one mutational step only. We must, however, also keep in mind that the coverage of samples of $B$. tropicus throughout its vast African range is far from being representative and therefore the 'endemicity' of the unique haplotypes cannot be evaluated with all certainty. The variability in haplotypes might also be reflected in shell shapes as outlined by an example from Lake Mafuro, in which two distinct haplotypes corresponded to distinct shell morphs (Additional file 1: Figure S1a, b). The Bulinus snails from Lake Kyaninga have shells that are quite distinct from the rest in the region (Additional file 1: Figure S1c).

One question relates to colonization history, i.e. where the lineages come from. In the case of B. tropicus, our results identified populations from across Africa as potential sources based on genetic affinities, both from nearby source of the Victoria-Nile-Albert system or places considerably far away in Tanzania or even West Africa. The co-occurrence of distantly related haplotypes in a single lake (e.g. Nkuruba or Nyabikere) points towards multiple colonization of the same lake system likely fostered by high propagule pressure. Sharing haplotypes regionally hints towards population dispersal by passive means since most of the lakes studied have no hydrological connection. A similar pattern has been found for fishes in the Fort Portal region [57]. MachadoSchiaffino et al. [58] studying the Bunyaruguru crater lakes discovered strong genetic and morphological differentiation whereby geographically close lakes tend to be genetically more similar. Such a general trend was not obvious when comparing the lakes based on the haplotype distribution in our study. 
It is important to notice that altitude reflecting climate parameters as earlier predicted [15], did not correlate with occurrence and diversity of snail populations. Rather, a more complex interplay of land use, lakes limnology, community resistance and stochasticity might account for the presence or absence of certain snail species and certain haplotypes in the crater lakes.

\section{Parasitological implications}

This study did not find an immediate risk for urogenital schistosomiasis based on the Bulinus snails identified. However, the identification of up to six partly highly divergent haplotypes in small and young isolated systems such as the crater lakes in Uganda, might hint to either extremely fast evolution or multiple invasions by vectors from various source populations. This involves humans most likely. If this is the case, other species of Bulinus and Biomphalaria might also potentially be introduced. Not only is the probability of the introduction of host snails likely to increase given increased mobility of people in Uganda and international migrations, such as refugees from the crisis regions in surrounding countries, but also are such human flows capable of dispersing non-native parasite strains with them. It should be kept in mind that for example in the neighboring Nile Province of South Sudan prevalence of S. haematobium infection was found to be more than $70 \%$ in school children [23] and that the few modelling attempts for urogenital schistosomiasis transmission risk suggest dynamic patterns for the near future [22].

In order to establish an enhanced model of schistosomiasis prevalence in the crater lakes region, a dedicated survey of infection rates among households adjacent to the lakes that are actually using the water resources of the lakes for various purposes should be conducted. The various ways of how and to what extent water is used directly or indirectly should be assessed and quantified, as the information available with regard to these activities is very limited. The role of human (indirect) transport of both host snails and parasites is likely to be more important than previously considered, due to the important flows of human populations in the region. Movement from regions with high infection risk sites around Lake Albert and Lake Victoria or other inland water bodies infested with schistosomiasis might enhance the prevalence of schistosomiasis in the western region of Uganda. There is also need for increased surveillance of new schistosomiasis outbreaks in the crater lakes region especially at higher altitudes in the face of the projected increase in temperature in the near future $[59,60]$ since crater lakes have shown to be sensitive to climate change $[61,62]$.
A largely neglected aspect here relates to schistosomiasis as a disease in livestock. Bulinus tropicus and $B$. forskalii found in the crater lakes are well-known intermediate hosts for bovine schistosome species such as $S$. bovis [63-67]. This parasite is responsible for a large proportion of livestock trematode infections [68], and the parasite's distribution overlaps largely with $S$. haematobium. Moreover, these two Schistosoma species have been shown to hybridize repeatedly, which triggered considerable parasitological and public health concern $[69,70]$. Thus, future surveys are suggested to include molecular screening of schistosome infections [71]. Schistosoma bovis infections of cattle have been confirmed from western Uganda [31]. Bulinus tropicus and B. forskalii are also intermediate hosts for Schistosoma margrebowiei and Calicophoron microbothrium [72, 73], with B. forskalii transmitting a wide range of parasites in Ethiopia [74]. Several trematode infections have been reported in B. forskalii [75]. Loker et al. [76] detected cercariae of seven species from naturally infected snails in north-west Tanzania. Our study thus points to a significant concern since livelihoods of people in the crater lake region of western Uganda predominantly depend on cows, sheep and goats, which are all susceptible to schistosomiasis and other trematodiases hosted by B. tropicus and B. forskalii [77]. The crater lakes are in close proximity to nature reserves and national parks that are home to one of the most diverse primate populations in Africa. It is thus noteworthy that zoonotic schistosomiasis is a significant concern at the humanwildlife interface that is currently largely underestimated [78], which makes the crater lake region further interesting for parasitological studies in addition to the relevance for increased intestinal schistosomiasis [79].

\section{Conclusions}

This first detailed malacological study of the crater lakes systems in western Uganda revealed a dominance of Bulinus species that are either not known at all (B. tropicus and $B$. forskalii) or not known to act as intermediate hosts of $S$. haematobium, the causative agent of human urogenital schistosomiasis in this region of Africa ( $B$. truncatus). The risk of contracting this form of schistosomiasis is thus currently very low. However, potential sources for intermediate host species and known regions with high prevalence rates, have been identified in comparatively close proximities to the study region (within a radius of $c .250 \mathrm{~km}$ ). The epidemiology of urogenital schistosomiasis is very dynamic and there is a potential for near-future occurrence in this part of Uganda. It is thus advisable to conduct more in-depth epidemiological studies in conjunction with the activities related to intestinal schistosomiasis. There is need for coordinated 
effort to document the genetic diversity of schistosome intermediate hosts from small-scale (in western Uganda) to large-scale (from Uganda as a country, to east Africa and the whole of Africa), so that an effort to eradicate the parasites via snail control from the natural system is based on informed grounds. A cautionary note is raised in terms of the veterinary importance of the gastropod species found. They both act as intermediate host for a variety of parasites including the species causing the majority of cases of livestock schistosomiasis, S. bovis. The impact of this finding is potentially of major importance but currently unstudied in the region. Such studies are needed as well as investigations into factors driving the presence of hosts and parasites in regions and ecosystems so far largely neglected but with the potential of becoming major transmission sites. This is significant, especially under the projected climate changes that will shift altitudinal limits of one of the most notorious tropical diseases that continues to be a major burden especially in sub-Saharan Africa.

\section{Supplementary information}

Supplementary information accompanies this paper at https://doi. org/10.1186/s13071-019-3811-2.

Additional file 1: Figure S1. Photographs of Bulinus tropicus from Lake Mafuro $(a, b)$ and a Bulinus species resembling B. globosus of Lake Kyaninga (c) showing variation in shell morphology. Both snails from Lake Mafuro are 11 mutation steps apart in the cox 1 network.

Additional file 2: Figure S2. Bayesian inference phylogenetic tree for Bulinus spp. based on cox1. Specimens are given with locality information (country of origin and localities in some cases). The DNA preparation numbers are provided. Crater lake names are provided and the two specific clades of B. forskalii (Clade 1) and B. tropicus (Clade 2) are highlighted with light grey boxes. Crater lake populations are represented at the end of the branch by red boxes, while regional and non-regional (= others) populations are demonstrated by green and grey boxes, respectively. Outgroup taxa are not shown. This tree is the full version of the collapsed tree in Fig. 3. Bayesian posterior probabilities (pp) are given for deeper nodes (when $\mathrm{pp} \geq 0.5$ ). The scale-bar represents substitutions per site according to the applied model of sequence evolution. The number of individuals per haplotype is shown in parentheses for the two specific clades (for details see Figs. 4, 5)

Additional file 3: Table S1. Haplotype sequence matrix for Bulinus tropicus in 31 crater lakes of western Uganda. Abbreviations: NL, total number of haplotypes per lake; $\mathrm{NH}$, total number of haplotype frequency (based on a 95\% connection limit). For details of 'lake codes'see Table 1.

\section{Abbreviations}

AIDS: acquired immune deficiency syndrome; a.s.l.: above sea level; cox1: mitochondrial cytochrome $c$ oxidase subunit 1 gene; CTAB: cetyl trimethyl ammonium bromide; DNA: deoxyribonucleic acid; DRC: Democratic Republic of the Congo; MEGA: molecular evolutionary genetics analysis; NTDs: neglected tropical diseases; PAST: paleontological statistics; PCR: polymerase chain reaction; UGSB: University of Giessen Systematics and Biodiversity collection.

\section{Acknowledgements}

We thank the laboratory assistant Ms Silvia Nachtigall for her technical assistance in the laboratory. Support from colleagues at Mbarara University of Science and Technology (MUST) is appreciated, especially of Julius Bunny
Lejju for his assistance towards acquiring research permits and Bosco Kimenye for his company in the field as a driver. We are grateful for the Bulinus samples of Kahirimbi western Uganda from Joseph Jude Agaba. Paul-Emile Desaulles, University of Lausanne, Switzerland is acknowledged for his help in the field for the material collected in 2016. The National Council for Science and Technology and Uganda Wildlife Authority kindly issued permits to conduct this study. Thies Geertz and Daniel Engelhard are gratefully acknowledged for their field work in 2010. The comments of three anonymous reviewers helped improving a previous version of the manuscript and are gratefully acknowledged.

\section{Authors' contributions}

IT and CA conceived the study. IT did field work, produced and analyzed the molecular data and drafted the tables/figures. IT and CA drafted the initial manuscript, while the latter is the overall supervisor of the study. CC was involved in data analyses, drafting the manuscript and fine-tuning the tables/ figures. MCD and JT conducted significant parts of the field sampling. GKR was involved in planning and organizing the study and helped with permits and logistics in the field as well as in drafting the initial manuscript. All authors read and approved the final manuscript.

\section{Funding}

IT is supported by a PhD scholarship of the German Academic Exchange Service (DAAD).

\section{Availability of data and materials}

Data supporting the conclusions of this article are included within the article and its additional files. The newly generated sequences were submitted to the GenBank database under the accession numbers MN551500-MN551585. The datasets generated and analysed during the present study are available in the University of Giessen Systematics and Biodiversity repository and are available upon reasonable request.

\section{Ethics approval and consent to participate}

This study was approved by Uganda National Council for Science and Technology (UNCST) (research clearance reference number NS20ES).

\section{Consent for publication}

Not applicable.

\section{Competing interests}

The authors declare that they have no competing interests.

\section{Author details}

1 Department of Animal Ecology and Systematics, Justus Liebig University Giessen, Giessen, Germany. ${ }^{2}$ Rwanda Wild life Conservation Association, Kigali, Rwanda. ${ }^{3}$ Department of Biology, Mbarara University of Science and Technology, Mbarara, Uganda. ${ }^{4}$ Department of Biology, Royal Museum for Central Africa, Leuvensesteenweg 13, 3080 Tervuren, Belgium. ${ }^{5}$ Limnology Research Unit, Ghent University, K. L. Ledeganckstraat 35, 9000 Ghent, Belgium.

Received: 29 April 2019 Accepted: 15 November 2019

Published online: 27 November 2019

\section{References}

1. Bergquist R, Zhou XN, Rollinson D, Reinhard-Rupp J, Klohe K. Elimination of schistosomiasis: the tools required. Infect Dis Poverty. 2017;6:158.

2. Hotez PJ, Kamath A. Neglected tropical diseases in sub-Saharan Africa: review of their prevalence, distribution, and disease burden. PLoS Negl Trop Dis. 2009;3:e412

3. van der Werf MJ, de Vlas SJ, Brooker S, Looman CW, Nagelkerke NJ, Habbema JD, Engels D. Quantification of clinical morbidity associated with schistosome infection in sub-Saharan Africa. Acta Trop. 2003;86:125-39.

4. King CH. Parasites and poverty: the case of schistosomiasis. Acta Trop. 2010;113:95-104.

5. Brindley PJ, Hotez PJ. Break out: urogenital schistosomiasis and Schistosoma haematobium infection in the post-genomic era. PLoS Negl Trop Dis. 2013;7:e1961. 
6. Colley DG, Bustinduy AL, Secor WE, King CH. Human schistosomiasis. Lancet. 2014;383:2253-64.

7. Rinaldi G, Okatcha TI, Popratiloff A, Ayuk MA, Suttiprapa S, Mann VH, et al. Genetic manipulation of Schistosoma haematobium, the neglected schistosome. PLoS Negl Trop Dis. 2011;5:e1348.

8. Rollinson D, Webster JP, Webster B, Nyakaana S, Jørgensen A, Stothard JR. Genetic diversity of schistosomes and snails: implications for control. Parasitology. 2009;136:1801-11.

9. Loewenberg S. Uganda's struggle with schistosomiasis. Lancet. 2014;383:1707-8

10. Adriko M, Tinkitina B, Tukahebw EM, Standley CJ, Stothard JR, Kabatereine NB. The epidemiology of schistosomiasis in Lango region Uganda 60 years after Schwetz 1951: can schistosomiasis be eliminated through mass drug administration without other supportive control measures? Acta Trop. 2018;185:412-8.

11. Kabatereine NB, Brooker S, Tukahebwa EM, Kazibwe F, Onapa AW. Epidemiology and geography of Schistosoma mansoni in Uganda: implications for planning control. Trop Med Int Health. 2004;9:372-80.

12. Kazibwe F, Makanga B, Rubaire-Akiiki C, Ouma J, Kariuki C, Kabatereine NB, et al. Transmission studies of intestinal schistosomiasis in Lake Albert, Uganda and experimental compatibility of local Biomphalaria spp. Parasitol Int. 2010;59:49-53.

13. Ongom VL, Bradley DJ. The epidemiology and consequences of Schistosoma mansoni infection in West Nile, Uganda. I. Field studies of a community at Panyagoro. Trans R Soc Trop Med Hyg. 1972;66:835-51.

14. Standley CJ, Goodacre SL, Wade CM, Stothard JR. The population genetic structure of Biomphalaria choanomphala in Lake Victoria, East Africa: implications for schistosomiasis transmission. Parasit Vectors. 2014;7:524.

15. John R, Ezekiel M, Philbert C, Andrew A. Schistosomiasis transmission at high altitude crater lakes in western Uganda. BMC Infect Dis. 2008;8:110.

16. Lachish T, Tandlich M, Grossman T, Schwartz E. High rate of schistosomiasis in travelers after a brief exposure to the high-altitude Nyinambuga crater lake, Uganda. Clin Infect Dis. 2013:57:1461-4.

17. Melack JM. Morphometric, physical and chemical features of the volcanic crater lakes of western Uganda. Arch Hydrobiol. 1978;84:430-53.

18. Mills K. Ugandan crater lakes: limnology, palaeolimnology and palaeoenvironmental history. PhD Thesis, Loughborough University, London; 2009.

19. Rumes $B$, Eggermont $H$, Verschuren D. Distribution and faunal richness of Cladocera in western Uganda crater lakes. Hydrobiologia. 2011;676:39.

20. Hartter J, Stampone MD, Ryan SJ, Kirner K, Chapman CA, Goldman A. Patterns and perceptions of climate change in a biodiversity conservation hotspot. PloS One. 2012;7:e32408.

21. Madinga J, Linsuke S, Mpabanzi L, Meurs L, Kanobana K, Speybroeck N, et al. Schistosomiasis in the Democratic Republic of Congo: a literature review. Parasit Vectors. 2015;8:601

22. Brooker S, Hay SI, Issae W, Hall A, Kihamia CM, Lwambo NJ, et al. Predicting the distribution of urinary schistosomiasis in Tanzania using satellite sensor data. Trop Med Int Health. 2001;6:998-1007.

23. Deganello R, Cruciani M, Beltramello C, Duncan O, Oyugi V, Montresor A. Schistosoma hematobium and S. mansoni among children, southern Sudan. Emerg Infect Dis. 2007;13:1504-6.

24. Sokolow SH, Wood CL, Jones IJ, Swartz SJ, Lopez M, Hsieh MH, et al. Global assessment of schistosomiasis control over the past century shows targeting the snail intermediate host works best. PLoS Negl Trop Dis. 2016;7:e0004794.

25. Abe E, Guo YH, Shen H, Mutsaka-Makuvaza M, Habib M, Xue JB, et al. Phylogeography of Bulinus truncatus (Audouin, 1827) (Gastropoda: Planorbidae) in selected African countries. Trop Med Infect Dis. 2018;3:127.

26. Brown DS. Freshwater snails of Africa and their medical importance. 2nd ed. London: Taylor \& Francis; 1994.

27. Madsen H. Schistosoma intermediate host snails. In: Jamieson BGM, editor. Schistosoma. Biology, pathology and control. Boca Raton: CRC Press; 2017. p. 46-63.

28. Jørgensen A, Madsen H, Nalugwa A, Nyakaana S, Rollinson D, Stothard JR, et al. A molecular phylogenetic analysis of Bulinus (Gastropoda: Planorbidae) with conserved nuclear genes. Zool Scr. 2011;40:126-36.

29. Jørgensen A, Jørgensen LV, Kristensen TK, Madsen H, Stothard JR. Molecular phylogenetic investigations of Bulinus (Gastropoda: Planorbidae) in Lake Malawi with comments on the topological incongruence between DNA loci. Zool Scr. 2007;36:577-85.
30. Kane RA, Stothard JR, Emery AM, Rollinson D. Molecular characterization of freshwater snails in the genus Bulinus: a role for barcodes? Parasit Vectors. 2008;1:15.

31. Stothard JR, Lockyer AE, Kabatereine NB, Tukahebwa EM, Kazibwe F, Rollinson D, et al. Schistosoma bovis in western Uganda. J Helminthol. 2004;3:281-4.

32. Nalugwa A, Jørgensen A, Nyakaana S, Kristensen TK. Molecular phylogeny of Bulinus (Gastropoda: Planorbidae) reveals the presence of three species complexes in the Albertine Rift freshwater bodies. Int J Genet Mol Biol. 2010;2:130-9.

33. Mandahl-Barth $\mathrm{G}$. The freshwater mollusks of Uganda and adjacent territories. Tervuren: Musée Royal de l'Afrique Centrale; 1954.

34. Schumann A, Muwanga A, Lehto T, Staudt M, Schlüter T, Kato V, Namboyera A. Ugandan geosites. Geol Today. 2015;31:59-67.

35. Cocquyt C, Plisnier PD, Gelorini V, Rumes B, Verschuren D. Observations on the limnology and phytoplankton community of crater Lake Kyaninga (Uganda), with special attention to its diatom flora. Plant Ecol Evol. 2010;143:365-77.

36. Efitre J, Murie DJ, Chapman LJ. Age validation, growth and mortality of introduced Tilapia zillii in crater Lake Nkuruba, Uganda. Fish Manag Ecol. 2016;23:66-75.

37. Albrecht C, Wilke T, Kuhn K, Streit B. Convergent evolution of shell shape in freshwater limpets: the African genus Burnupia. Zool J Linn Soc. 2004;140:577-86

38. Folmer O, Black M, Hoeh W, Lutz R, Vrijenhoek R. DNA primers for amplification of mitochondrial cytochrome c oxidase subunit I from diverse metazoan invertebrates. Mol Mar Biol Biotechnol. 1994;5:294-9.

39. Wilke T, Davis GM. Infraspecific mitochondrial sequence diversity in Hydrobia ulvae and Hydrobia ventrosa (Hydrobiidae: Rissooidea: Gastropoda): do their different life histories affect biogeographic patterns and gene flow? Biol J Linn Soc Lond. 2000:70:89-105.

40. Diehl E, Jauker B, Albrecht C, Wilke T, Wolters V. GIEßEN: university collections: Justus-Liebig University Gießen. In: Beck LA, editor. Zoological collections of Germany. Natural history collections. Cham: Springer; 2018. p. 373-81.

41. Hall TA. BioEdit: a user-friendly biological sequence alignment editor and analysis program for Windows 95/98/NT. Nucleic Acids Symp Ser. 1999:41:95-8.

42. Ronquist F, Sanmartín I. Phylogenetic methods in biogeography. Annu Rev Ecol Evol Syst. 2011;42:441-64.

43. Darriba D, Taboada GL, Doallo R, Posada D. jModelTest 2: more models, new heuristics and parallel computing. Nat Methods. 2012;9:772.

44. Drummond AJ, Rambaut A. BEAST: Bayesian evolutionary analysis by sampling trees. BMC Evol Biol. 2007;7:214.

45. Clement M, Posada DC, Crandall KA. TCS: a computer program to estimate gene genealogies. Mol Ecol. 2000;9:1657-9.

46. Hammer $\varnothing$, Harper DA, Ryan PD. PAST: paleontological statistics software package for education and data analysis. Palaeontol Electron. 2001;4:9.

47. Brown DS. Freshwater gastropod mollusca from Ethiopia. Bull Br Mus Nat Hist Zool. 1965;12:37-94.

48. Labbo R, Djibrilla A, Zamanka H, Garba A, Chippaux JP. Bulinus forskalii: a new potential intermediate host for Schistosoma haematobium in Niger. Trans R Soc Trop Med Hyg. 2007:101:847-8.

49. Ryves DB, Mills K, Bennike O, Brodersen KP, Lamb AL, Leng MJ, et al. Environmental change over the last millennium recorded in two contrasting crater lakes in western Uganda, eastern Africa (Lakes Kasenda and Wandakara). Quat Sci Rev. 2011;30:555-69.

50. Nalugwa A, Kristensen TK, Nyakaana S, Jørgensen A. Mitochondrial DNA variations in sibling species of the Bulinus truncatus/tropicus complex in Lake Albert, western Uganda. Zool Stud. 2010;49:515-22.

51. Plam M, Jørgensen A, Kristensen TK, Madsen H. Sympatric Biomphalaria species (Gastropoda: Planorbidae) in Lake Albert, Uganda, show homoplasies in shell morphology. Afr Zool. 2008:43:34-44.

52. Rowel C, Fred B, Betson M, Sousa-Figueiredo JC, Kabatereine NB, Stothard JR. Environmental epidemiology of intestinal schistosomiasis in Uganda: population dynamics of Biomphalaria (Gastropoda: Planorbidae) in Lake Albert and Lake Victoria with observations on natural infections with digenetic trematodes. Biomed Res Int. 2015;2015:717261.

53. Standley CJ, Wade CM, Stothard JR. A fresh insight into transmission of schistosomiasis: a misleading tale of Biomphalaria in Lake Victoria. PloS One. 2011;6:e26563. 
54. Zein-Eddine R, Djuikwo-Teukeng FF, Al-Jawhari M, Senghor B, Huyse T, Dreyfuss $G$. Phylogeny of seven Bulinus species originating from endemic areas in three African countries, in relation to the human blood fluke Schistosoma haematobium. BMC Evol Biol. 2014;14:271.

55. Zein-Eddine R, Djuikwo-Teukeng FF, Dar Y, Dreyfuss G, Van den Broeck F. Population genetics of the Schistosoma snail host Bulinus truncatus in Egypt. Acta Trop. 2017;172:36-43.

56. Wilke T, Schultheiß R, Albrecht C. As time goes by: a simple fool's guide to molecular clock approaches in invertebrates. Am Malacol Bull. 2009;27:25-46.

57. Lemoine M, Barluenga M, Lucek K, Mwaiko S, Haesler M, Chapman $L J$, et al. Recent sympatric speciation involving habitat-associated nuptial colour polymorphism in a crater lake cichlid. Hydrobiologia. 2019;832:297-315.

58. Machado-Schiaffino G, Kautt AF, Kusche H, Meyer A. Parallel evolution in Ugandan crater lakes: repeated evolution of limnetic body shapes in haplochromine cichlid fish. BMC Evol Biol. 2015;15:9.

59. McCreesh N, Arinaitwe M, Arineitwe W, Tukahebwa EM, Booth M. Effect of water temperature and population density on the population dynamics of Schistosoma mansoni intermediate host snails. Parasit Vectors. 2014;7:503.

60. Stensgaard AS, Utzinger J, Vounatsou P, Hürlimann E, Schur N, Saarnak CF, et al. Large-scale determinants of intestinal schistosomiasis and intermediate host snail distribution across Africa: does climate matter? Acta Trop. 2013;128:378-90.

61. Saulnier-Talbot É, Chapman L, Efitre J, Simpson K, Gregory-Eaves I. Longterm hydrologic fluctuations and dynamics of primary producers in a tropical crater lake. Front Ecol Evol. 2018;6:223.

62. Saulnier-Talbot É, Gregory-Eaves I, Simpson KG, Efitre J, Nowlan TE, Taranu ZE, et al. Small changes in climate can profoundly alter the dynamics and ecosystem services of tropical crater lakes. Plos One. 2014;9:e86561.

63. Kinoti G. Observations on the transmission of Schistosoma haematobium and Schistosoma bovis in the Lake Region of Tanganyika. Bull World Health Organ. 1964;31:815-23.

64. Southgate VR, Knowles RJ. Observations on Schistosoma bovis Sonsino, 1876. J Nat Hist. 1975;9:273-314.

65. Southgate VR, Brown DS, Rollinson D, Ross GC, Knowles RJ. Bulinus tropicus from Central Kenya acting as a host for Schistosoma bovis. Z Parasitenkd. 1985;71:61-9.

66. Mutani A, Christensen NØ, Frandsen F. Studies on the relationship between Schistosoma and their intermediate hosts. V. The genus Bulinus and Schistosoma bovis from Iringa, Tanzania. Z Parasitenkd. 1983;69:483-7.

67. Mwambungu JA. Transmission of Schistosoma bovis in Mkulwe (Mbozi district, Mbeya region, southern highlands of Tanzania). J. Helminthol. 1988;62:29-32.

68. De Bont J, Vercruysse J. The epidemiology and control of cattle schistosomiasis. Parasitol Today. 1997;13:255-62.

69. Huyse T, Webster BL, Geldof S, Stothard JR, Diaw OT, Polman K, et al. Bidirectional introgressive hybridization between a cattle and human schistosome species. PLoS Pathog. 2009;5:e1000571.
70. Leger E, Webster JP. Hybridizations within the genus Schistosoma: implications for evolution, epidemiology and control. Parasitology. 2017; 144:65-80.

71. Minetti C, Lacourse EJ, Reimer L, Stothard JR. Focusing nucleic acid-based molecular diagnostics and xenomonitoring approaches for human helminthiases amenable to preventive chemotherapy. Parasitol Open. 2016;2:e16.

72. Southgate VR, Howard GW, Rollinson D, Brown DS, Ross GC, Knowles RJ. Bulinus tropicus, a natural intermediate host for Schistosoma margrebowiel in Lochinvar National Park, Zambia. J Helminthol. 1985;59:153-5.

73. Dinnik JA, Dinnik NN. The schistosomes of domestic ruminants in eastern Africa. Bull Epizoot Dis Afr. 1965;13:341-59.

74. Graber $M$, Daynès $P$. Mollusques vecteurs de trématodoses humaines et animales en Ethiopie. Rev Elev Med Vet Pay. 1974;27:307-22.

75. Hira PR. Studies on the capability of the snail transmitting urinary schistosomiasis in western Nigeria to survive dry conditions. West Afr Med J Niger Pract. 1968;17:153-60.

76. Loker ES, Moyo HG, Gardner SL. Trematode-gastropod associations in nine non-lacustrine habitats in the Mwanza region of Tanzania. Parasitology. 1981;83:381-99.

77. Rollinson D, Stothard JR, Southgate VR. Interactions between intermediate snail hosts of the genus Bulinus and schistosomes of the Schistosoma haematobium group. Parasitology. 2001;123(Suppl.):S245-60.

78. Standley CJ, Mugisha L, Dobson AP, Stothard JR. Zoonotic schistosomiasis in non-human primates: past, present and future activities at the humanwildlife interface in Africa. J Helminthol. 2012;86:131-40.

79. Stanton MC, Adriko M, Arinaitwe M, Howell A, Davies J, Allison G, et al. Intestinal schistosomiasis in Uganda at high altitude (>1400 m): malacological and epidemiological surveys on Mount Elgon and in Fort Portal crater lakes reveal extra preventive chemotherapy needs. Infect Dis Poverty. 2017:6:34.

80. Akinwale OP, Kane RA, Rollinson D, Stothard JR, Ajayi MB, Akande DO, et al. Molecular approaches to the identification of Bulinus species in south-west Nigeria and observations on natural snail infections with schistosomes. J Helmintol. 2011;85:283-93.

81. Allan F, Sousa-Figueiredo JC, Emery AM, Paulo R, Mirante C, Sebastião A, et al. Mapping freshwater snails in north-western Angola: distribution, identity and molecular diversity of medically important taxa. Parasit Vectors. 2017;10:460.

82. Pennance T, Ame SM, Amour AK, Suleiman KR, Allan F, Rollinson D, et al. Occurrence of Schistosoma bovis on Pemba Island, Zanzibar: implications for urogenital schistosomiasis transmission monitoring. Parasitology. 2018;145:1727-31.

\section{Publisher's Note}

Springer Nature remains neutral with regard to jurisdictional claims in published maps and institutional affiliations.

\footnotetext{
Ready to submit your research? Choose BMC and benefit from:

- fast, convenient online submission

- thorough peer review by experienced researchers in your field

- rapid publication on acceptance

- support for research data, including large and complex data types

- gold Open Access which fosters wider collaboration and increased citations

- maximum visibility for your research: over $100 \mathrm{M}$ website views per year
}

At BMC, research is always in progress.

Learn more biomedcentral.com/submissions 